\title{
Article \\ A Comparison of Fuzzy-Based Energy Management Systems Adjusted by Nature-Inspired Algorithms
}

\author{
Diego Arcos-Aviles 1,2,*D, Diego Pacheco ${ }^{1,2}$, Daniela Pereira ${ }^{1,2}$, Gabriel Garcia-Gutierrez ${ }^{1,2}$, \\ Enrique V. Carrera ${ }^{1,3} \mathbb{D}^{\text {, }}$, Alexander Ibarra ${ }^{1,2}$, Paúl Ayala ${ }^{1,2}$, Wilmar Martínez ${ }^{4,5}$ and Francesc Guinjoan ${ }^{6} \mathbb{D}$
}

1 Departamento de Eléctrica, Electrónica y Telecomunicaciones, Universidad de las Fuerzas Armadas ESPE, Av. General Rumiñahui s/n, 171103 Sangolquí, Ecuador; drpacheco254@gmail.com (D.P.); mdpereira1404@gmail.com (D.P.); gmgarcia94@gmail.com (G.G.-G.); evcarrera@espe.edu.ec (E.V.C.); oaibarra@espe.edu.ec (A.I.); jpayala@espe.edu.ec (P.A.)

2 Research Group of Propagation, Electronic Control, Networking (PROCONET), Universidad de las Fuerzas Armadas ESPE, Av. General Rumiñahui s/n, 171103 Sangolquí, Ecuador

3 WICOM-Energy Research Group, Universidad de las Fuerzas Armadas ESPE, Av. General Rumiñahui s/n, 171103 Sangolquí, Ecuador

4 Department of Electrical Engineering, ESAT, KU Leuven, Agoralaan gebouw B bus 8, 3590 Diepenbeek, Belgium; wilmar.martinez@kuleuven.be

5 EnergyVille-Thor Park 8310, 3600 Genk, Belgium

6 Department of Electronics Engineering, Escuela Técnica Superior de Ingenieros de Telecomunicación de Barcelona, Universitat Politècnica de Catalunya. C. Jordi Girona 31, 08034 Barcelona, Spain; francesc.guinjoan@upc.edu

* Correspondence: dgarcos@espe.edu.ec

check for updates

Citation: Arcos-Aviles, D.; Pacheco, D.; Pereira, D.; Garcia-Gutierrez, G.; Carrera, E.V.; Ibarra, A.; Ayala, P.; Martínez, W.; Guinjoan, F. A Comparison of Fuzzy-Based Energy Management Systems Adjusted by Nature-Inspired Algorithms. Appl. Sci. 2021, 11, 1663. https://doi.org/ 10.3390/app11041663

Academic Editor: Sang-Hyun Lee

Received: 18 January 2021

Accepted: 9 February 2021

Published: 12 February 2021

Publisher's Note: MDPI stays neutral with regard to jurisdictional claims in published maps and institutional affiliations.

Copyright: (c) 2021 by the authors. Licensee MDPI, Basel, Switzerland. This article is an open access article distributed under the terms and conditions of the Creative Commons Attribution (CC BY) license (https:/ / creativecommons.org/licenses/by/ $4.0 /)$.
Abstract: The growing energy demand around the world has increased the usage of renewable energy sources (RES) such as photovoltaic and wind energies. The combination of traditional power systems and RESs has generated diverse problems due especially to the stochastic nature of RESs. Microgrids (MG) arise to address these types of problems and to increase the penetration of RES to the utility network. A microgrid includes an energy management system (EMS) to operate its components and energy sources efficiently. The objectives pursued by the EMS are usually economically related to minimizing the operating costs of the MG or maximizing its income. However, due to new regulations of the network operators, a new objective related to the minimization of power peaks and fluctuations in the power profile exchanged with the utility network has taken great interest in recent years. In this regard, EMSs based on off-line trained fuzzy logic control (FLC) have been proposed as an alternative approach to those based on on-line optimization mixed-integer linear (or nonlinear) programming to reduce computational efforts. However, the procedure to adjust the FLC parameters has been barely addressed. This parameter adjustment is an optimization problem itself that can be formulated in terms of a cost/objective function and is susceptible to being solved by metaheuristic nature-inspired algorithms. In particular, this paper evaluates a methodology for adjusting the FLC parameters of the EMS of a residential microgrid that aims to minimize the power peaks and fluctuations on the power profile exchanged with the utility network through two nature-inspired algorithms, namely particle swarm optimization and differential evolution. The methodology is based on the definition of a cost function to be optimized. Numerical simulations on a specific microgrid example are presented to compare and evaluate the performances of these algorithms, also including a comparison with other ones addressed in previous works such as the Cuckoo search approach. These simulations are further used to extract useful conclusions for the FLC parameters adjustment for off-line-trained EMS based designs.

Keywords: microgrid; energy management system; fuzzy logic control; particle swarm optimization; differential evolution; cuckoo search algorithm; nature-inspired algorithms 


\section{Introduction}

The growing energy demand in the industrial, commercial, and residential sectors around the world has significantly increased energy consumption during the last decades. The total primary energy supply, or the energy available in nature before being converted or transformed, has increased from 6.1 billion tons of oil equivalent in 1973 to 13.7 billion tons in 2016 [1]. This increment in energy consumption has generated a negative impact on the concentration of greenhouse gases [2], indicating that many countries focus their resources on improving energy efficiency and increasing the production of clean energy. As a consequence of these actions, there has been a sustained increment in the usage of renewable energy sources (RES), where photovoltaic and wind energies the ones with the highest growth worldwide [3].

However, new problems have appeared when RESs are combined with traditional sources of energy [3]. For instance, unexpected fluctuations in the response of RES can affect the voltage and frequency of the network, constrained power electronics requirements, different control and dispatch methods, etc. Thus, the microgrid (MG) concept appeared to solve some of these drawbacks [4]. A microgrid is a low-voltage distribution network consisting of loads, distributed generation elements, and energy storage systems (ESS), which can be connected to the mains at a single point of common coupling (PCC). It has an associated energy management system (EMS) that allows the reliable, safe, and economic operation of the elements within the microgrid [5].

An EMS controls the power flux of different microgrid elements to achieve certain goals, such as minimize operating costs or maximize revenues [6,7]. Several EMSs have been presented in the literature, each of them considering different types of MG architecture (i.e., AC, DC, and hybrid AC-DC microgrids) [8-10] and pursue different objectives under different conditions [11,12]. For instance, [13] presents a stochastic risk-constrained framework for short-term optimal scheduling of autonomous microgrid to maximize the expected profit of the microgrids operator. In [14], an intelligent EMS using mixed-integer linear programming of grid-connected home-type microgrid is presented. This approach reduced energy costs of non-dispatchable distributed energy resources. The study in [15] presents the design of an EMS for a grid-connected microgrid equipped with photovoltaic $(\mathrm{PV})$ generator to manage the load supply with the maximum exploitation of solar energy and improving the thermal comfort of the occupants.

However, RES such as wind and PV feed power into the grid in a very variable way, directly related to the variability of the energy source itself (i.e., wind and irradiance). As these power sources are set to attain very high degrees of penetration level in the current grid, this power variability is of great concern for grid operators [16-18]. Therefore, various studies have been developed in recent years to minimize power fluctuations (i.e., ramp-rates) on the power exchanged with the grid [19-21]. For instance, the study in [19] analyzes the effect of smoothing the tie-line power fluctuations for grid-connected industrial microgrids using demand-side approach. In addition, the studies in [20] and [21] present a heuristic design of an EMS of residential electrical and electro-thermal gridconnected microgrids, respectively, including an ESS, RES, and a residential electrical load.

Due to its heuristic nature, some studies have focused on the design of the EMS using expert knowledge rule-based systems since they have proven to be easy to implement and low computational run time cost than other sophisticated analytical solutions [22,23]. Thus, a fuzzy logic control (FLC) EMS of two inputs, one output, and 25 rules is developed in [24] and experimentally validated in [25]. The same approach, but now using generation and demand forecasts is described and validated in [26]. These EMSs, and others designs based on FLC [27], pursue a common main objective, which consists of smoothing the power profile exchanged from the MG to the utility network. However, the design of the FLC block involved within these EMSs requires the selection of several parameters such as the type and number of membership functions, rule base, and variation range of each variable. Therefore, a first approach to perform the parameter adjustment of an FLC controller that is part of the EMS of a residential grid-connected microgrid is developed 
in [28]. This approach performs an off-line parameter tuning of the FLC of an EMS using the real recorded data of RES production and load consumption in one year.

However, the selection of the FLC parameters can be seen as an optimization problem that could be formulated in terms of a cost/objective function [29]. Fortunately, in addition to costly and time-consuming traditional optimization techniques, several metaheuristic nature-inspired algorithms have been proposed to solve optimization problems in a wide range of applications [30-33]. Some examples of these nature-inspired algorithms that can be found in the literature are genetic algorithms [34], differential evolution (DE) [35], ant colony optimization [36], particle swarm optimization (PSO) [37], firefly algorithm [38], Cuckoo search (CS) [39], among others. In this regard, to improve the parameter adjustment procedure described in [28], a methodology based on the CS algorithm is presented in $[40,41]$. This approach is applied to the EMS of a residential grid-connected electro-thermal microgrid, improving its performance in terms of smoothing (i.e., minimizing power peaks and fluctuations) the power profile exchanged with the utility network.

Hence, to analyze the behavior of other nature-inspired algorithms, this paper evaluates a methodology for adjusting the FLC parameters of the EMS of a residential gridconnected electro-thermal microgrid through two metaheuristic nature-inspired algorithms, namely PSO and DE. Although there are many nature-inspired optimization algorithms, $\mathrm{PSO}, \mathrm{DE}$, and CS are the most classical examples of nature-inspired techniques that are based on different search strategies [42]. DE is a heuristic evolutionary optimization algorithm developed for solving real-valued numerical optimization problems [35]. It is a very effective global search algorithm with a simple mathematical structure. On the other hand, PSO is a stochastic and multi-agent parallel global-search technique [37], which, unlike DE, is based on the mathematical modeling of various collective behaviors of living creatures that display complex social conducts, allowing it to develop local solutions into global optimum solutions. Finally, the CS algorithm is a more recent alternative to PSO that models the obligate brood parasitism of some cuckoo species [39]. A global cost function, including all criteria used to evaluate the quality of the grid power profile, is formulated, which constitutes the optimization objective function. Results show that the evaluated nature-inspired algorithms present similar optimization performance. However, the CS algorithm offers some advantages related to the reduction of fluctuations and power peaks in the grid power profile. It is also important to mention that in terms of computing time, the PSO algorithm is faster than CS and DE algorithms. A comparison with an EMS strategy that uses an off-line parameter tuning for the FLC block [43] demonstrates that the CS, PSO, and DE algorithms get an acceptable response concerning the main objective pursued by the EMS (i.e., smoothing the power profile exchanged with the mains).

The main contributions of this paper are listed below:

1. A complete procedure for adjusting the parameters of an FLC block of the EMS of a residential grid connected electro-thermal microgrid using the PSO and DE algorithms.

2. A set of comparative one-year simulations and quantification of smoothing indexes, using real data, highlighting the advantages and disadvantages of each analyzed approach.

The remainder of this paper is organized as follows. Section 2 presents the architecture and operation of the electro-thermal microgrid under study. Section 3 describes the fitness function and presents the optimization matrix and search space used in this optimization problem. The PSO and DE algorithms are described in Sections 4 and 5, respectively. Section 6 presents the simulation and comparison results. Finally, Section 7 summarizes the main conclusions of this study. 


\section{Structure and Operation of the Grid-Connected Microgrid}

This study is an extension of the previous works [40,41], which present a methodology for adjusting the FLC parameters of the EMS of an electro-thermal microgrid employing the CS algorithm. The structure of the microgrid under analysis, as well as its operation in grid-connected mode, is presented below.

Note that the mathematical models of RESs, i.e., PV and wind turbine (WT), the domestic hot water system (DHW) system, the forecast of power generation and load demand, and the battery state-of-charge (SOC) estimator are not included in this study. However, for complete information on these models, the reader could refer to [27].

\subsection{Microgrid Structure}

The microgrid architecture comprises two main blocks, namely the electrical system and the DHW system $[27,43,44]$. The electrical system includes a hybrid renewable generation system comprising a PV generator of $6 \mathrm{kWp}$ and a WT of $6 \mathrm{~kW}$, an ESS consisting of a lead-acid battery bank with a rated capacity of $72 \mathrm{kWh}$, and a domestic load of $7 \mathrm{~kW}$, which includes typical domestic appliances, lighting, etc. The DHW system includes a solar thermal collector of $2 \mathrm{~kW}$, an electric water heater $(\mathrm{EWH})$ of $2 \mathrm{~kW}$, a thermal ESS consisting of a hot water tank of $800 \mathrm{~L}$ capacity, and thermal demand (i.e., DHW consumption) equivalent to $2 \mathrm{~kW}$. Figure 1 shows the microgrid architecture under study.

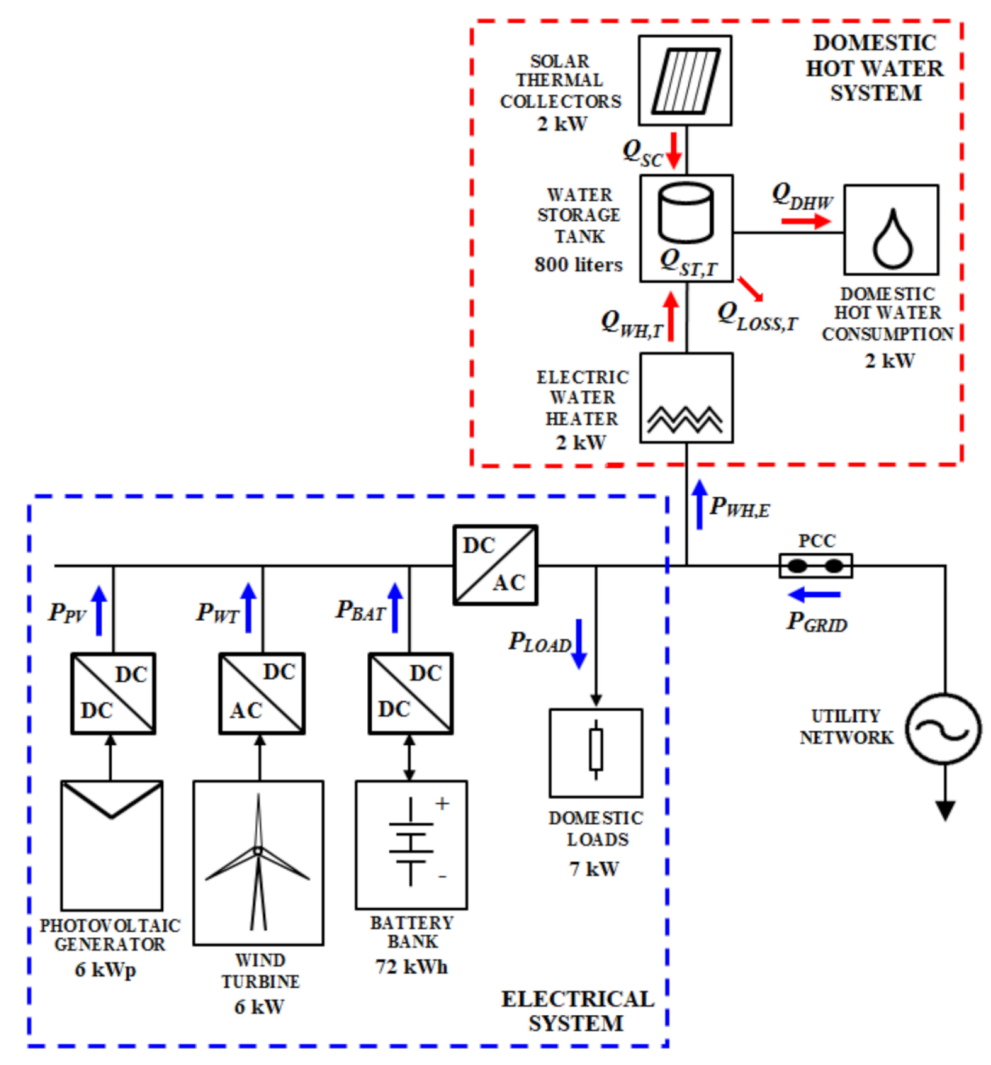

Figure 1. Electro-thermal microgrid architecture.

The microgrid shown in Figure 1 uses one-year real data of renewable power generation and load demand, provided every $15 \mathrm{~min}$ (i.e., sampling period of $T_{s}=900 \mathrm{~s}$ ), by the MG installed at Public University of Navarre (UPNa) (Pamplona, Spain: $42^{\circ} 49^{\prime} 06^{\prime \prime} \mathrm{N}$ $\left.1^{\circ} 38^{\prime} 39^{\prime \prime} \mathrm{O}\right)$. These power profiles are depicted in Figure 2. 


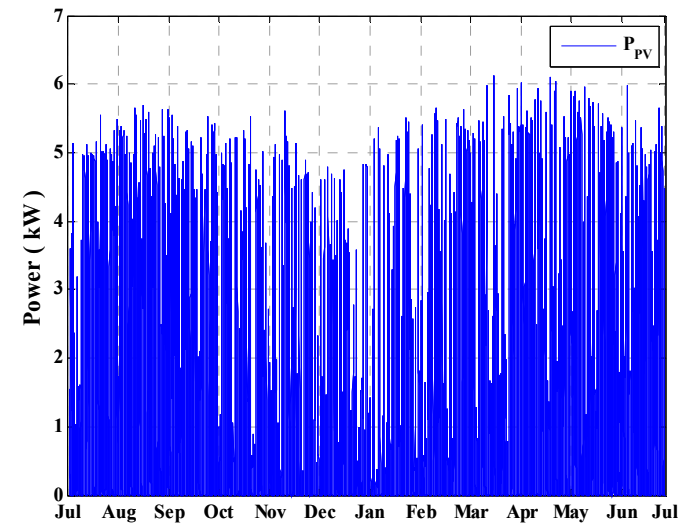

(a)

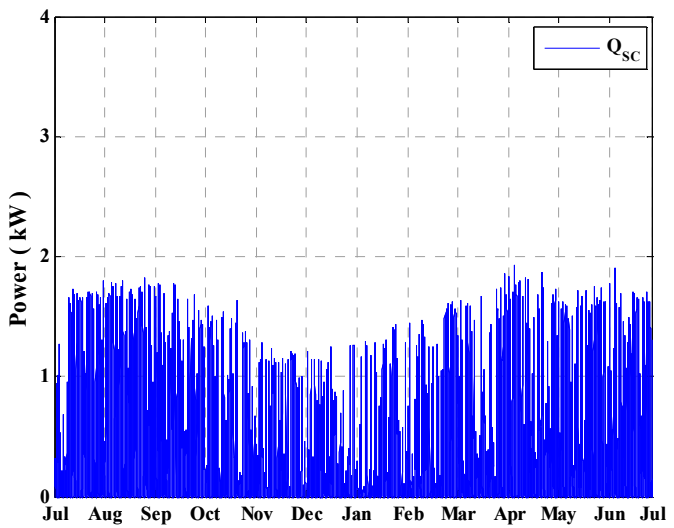

(c)

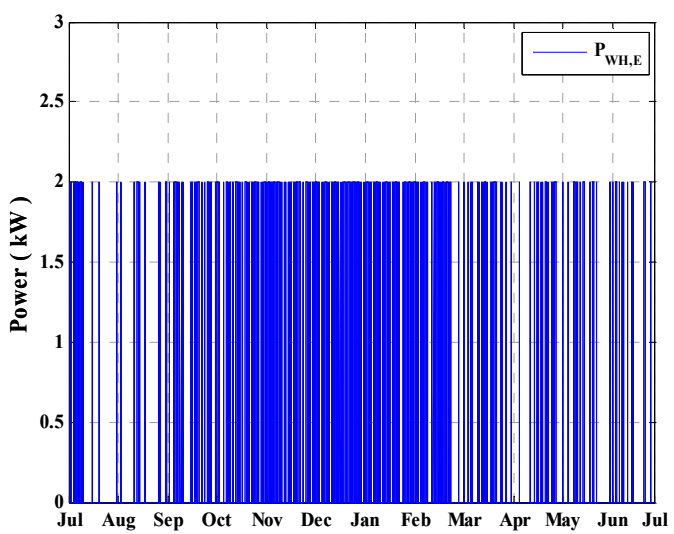

(e)

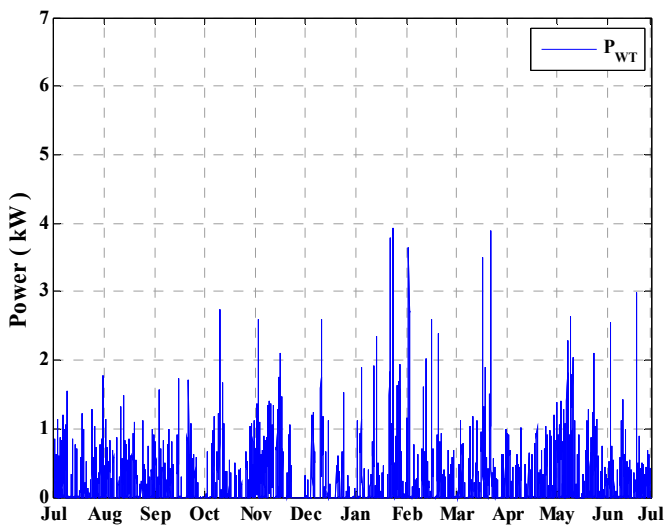

(b)

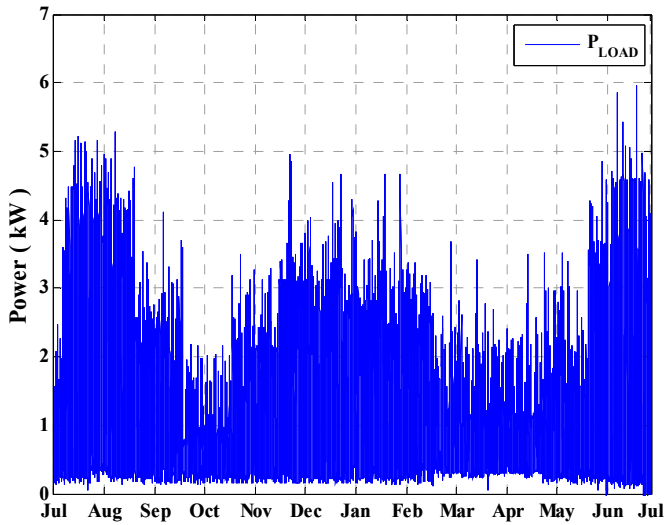

(d)

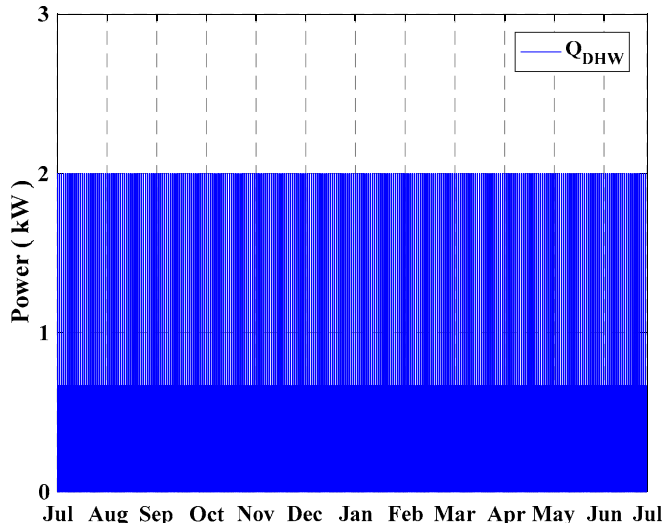

(f)

Figure 2. Microgrid power profiles: (a) Photovoltaic power, (b) wind turbine power, (c) solar thermal collector power, (d) domestic load demand, (e) electric water heater power, and (f) domestic hot water equivalent power.

\subsection{Microgrid Operation in Grid-Connected Mode}

In grid-connected mode, the microgrid under study is in charge of smoothing the grid power profile through suitable control of the power injected/absorbed by the battery ESS. The EMS is based on a control strategy described in [43]. The goal of the EMS is to perform the suitable use of the energy stored in the battery ESS to cover part of the energy required by the $\mathrm{EWH}$ for keeping the water temperature in the thermal storage between established limits.

In this regard, the control of the battery power, $P_{B A T}$, is indirectly performed by controlling the power supplied by the battery ESS for the EWH consumption, $P_{W H}^{B}$, and 
imposing the desired grid power profile, $P_{G R I D}$. In [43], the grid power profile is defined as the sum of three components, as follows:

$$
\begin{gathered}
P_{G R I D}(t)=P_{C T R}^{*}(t)+P_{S O C}(t)+P_{F L C}(t) \\
P_{B A T}(t)=P_{L G}(t)-P_{G R I D}(t)+P_{W H}^{B}(t) \\
P_{L G}(t)=P_{L O A D}(t)+P_{W H, E}(t)-P_{P V}(t)-P_{W T}(t)
\end{gathered}
$$

where $t$ is the current sample, $P_{C T R}^{*}$ is the output of a central moving average (CMA) filter, which establishes the MG average power profile, $P_{S O C}$ is the output of the battery control loop, which is used to keep the battery SOC close to the $75 \%$ of the battery rated capacity, $P_{F L C}$ is the output of an FLC block, which is used to smooth the grid power profile according to the microgrid power forecast error and the battery SOC [40,43], $P_{L G}$ is the microgrid net power, $P_{L O A D}$ is the domestic load demand, $P_{W H, E}$ is the EWH power, $P_{P V}$ is the photovoltaic power, and $P_{W T}$ is the wind turbine power.

The EMS block diagram comprises six blocks [43], see Figure 3, which regulates both the power delivered by the utility grid and the power injected or absorbed by the ESS.

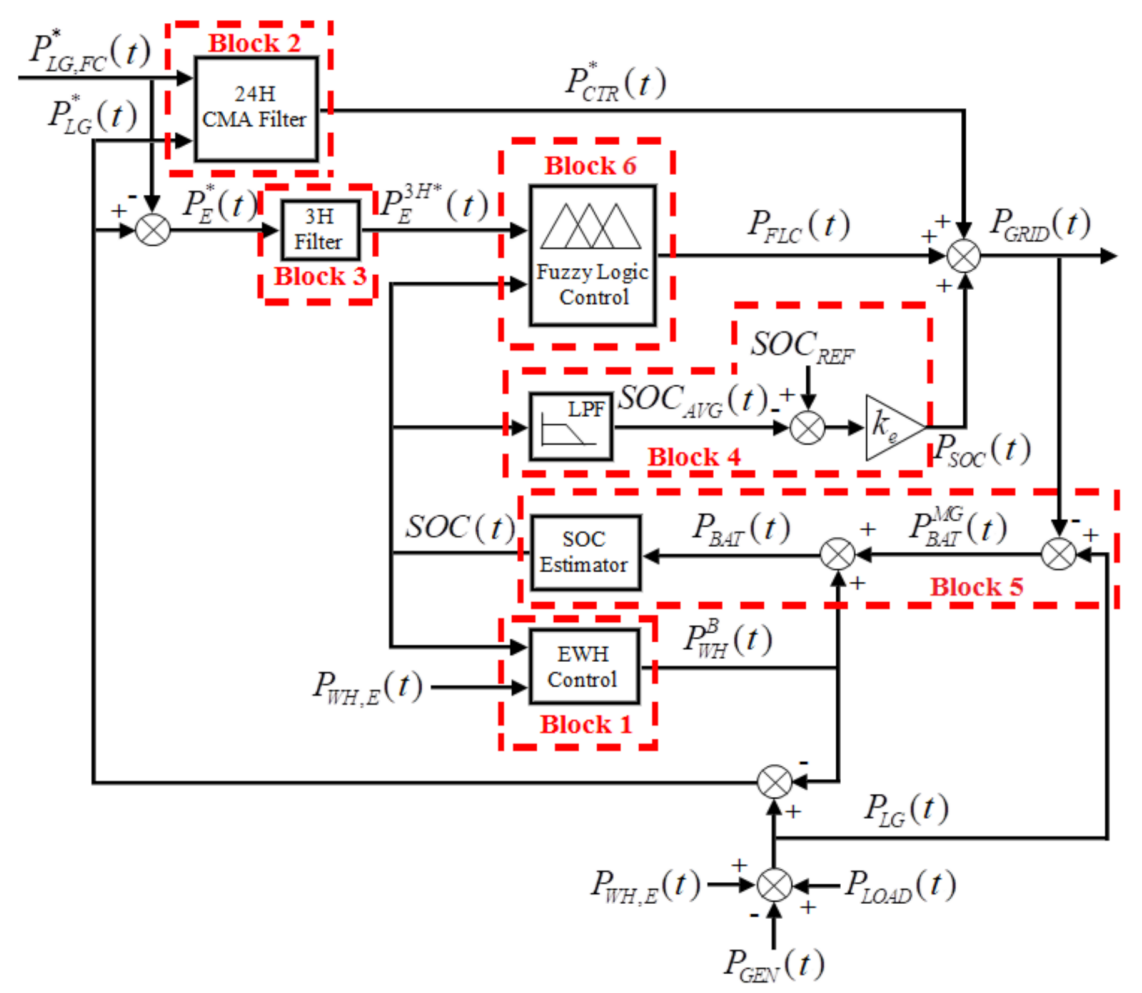

Figure 3. Energy management strategy block diagram [43]. (C2018 IEEE, Reprinted, with permission from D. Arcos-Aviles et al., "Fuzzy-based energy management of a residential electro-thermal microgrid based on power forecasting," in IECON 2018-44th Annual Conference of the IEEE Industrial Electronics Society, Washington, DC, USA, October 2018, pp. 1824-1829.

Where $P_{G E N}$ is the renewable power generation, $P_{L G}^{*}$ is the modified MG net power defines as $P_{L G}^{*}(t)=P_{L G}(t)-P_{W H}^{B}(t)$, being $P_{W H}^{B}$ the power injection to the EWH from the battery ESS, $P_{L G, F C}^{*}$ is the forecast of the modified MG net power, $P_{E}^{*}$ is the MG forecast error, $P_{E}^{3 H *}$ is the power forecast error of the previous 3-h, $S O C_{A V G}$ is the average battery SOC of the previous $24-\mathrm{h}, S O C_{R E F}$ is the battery $S O C$ reference value (i.e., $S O C_{R E F}=75 \%$ ), $k_{e}$ is the proportional gain constant (i.e., $k_{e}=0.05$ ), and $P_{B A T}^{M G}$ is an auxiliary variable used to compute the battery power. Note that the step-by-step design of the EMS is out of the scope of this paper. However, for complete descriptions of each block within the EMS design (see Figure 3), readers can refer to [43]. 
In the diagram shown in Figure 3, block number six constitutes the one that is responsible for smoothing the power profile exchanged with the grid. This block consists of an FLC that assumes a Mamdani-based inference and defuzzification method of the Center of Gravity of two input, one output, and 25 rules. The inputs of the FLC are the current battery SOC and the power forecast error of the previous 3-hours, $P_{E}^{3 H *}$, which is defined as:

$$
P_{E}^{3 H *}(t)=\left(1 / M_{3}\right) \sum_{k=1}^{M_{3}} P_{E}^{*}(t-k)
$$

where $k$ is the sample index, $M_{3}$ is the number of samples in 3-h, and $P_{E}^{*}$ is computed as $P_{E}^{*}(t)=P_{L G}^{*}(t)-P_{L G, F C}^{*}(t)$.

Regarding the design of the FLC, an offline parameter setting process, described in [28], is followed, which allows the adjustment of all parameters involved in the FLC, such as the number of membership functions (MFs) per input/output, type, mapping, and rule base. This process is performed considering the real recorded and forecasted data of renewable energy source electricity production and load demand for one year. This procedure leads to the MF for inputs and outputs shown in Figure 4 [45], with their respective variation ranges where $P_{e}=6 \mathrm{~kW} ; S O C_{M I N}=50 \%, S O C_{M A X}=100 \%, P_{N}=0.8 \mathrm{~kW}$, and $P_{P}=1.35 \mathrm{~kW}$, and the FLC rule base presented in Table 1. Note that the fuzzy subsets depicted in Figure 4 are denoted as NB, NM, NS, NSS, ZE, PSS, PS, PM, and PB, where B represents "Big", M "Medium", S "Small", SS "Smallest", N "Negative", P "Positive", and ZE "Zero".

Table 1. Heuristic approach rule base energy management system (EMS) [43].

\begin{tabular}{ccccccc}
\hline \multicolumn{3}{c}{$\boldsymbol{P}_{\text {FLC }}(n)$} & & \multicolumn{5}{c}{$P_{E}^{*}(n)$} \\
\cline { 3 - 7 } & & NB & NS & ZE & PS & PB \\
\hline \multirow{4}{*}{$S O C(n)$} & NB & PB & PM & PS & PM & PB \\
& NS & PM & PS & PSS & PS & PM \\
& ZE & NS & ZE & ZE & PSS & NSS \\
& PS & NM & NS & NSS & NS & NM \\
& PB & NB & NSS & NM & NM & NB \\
\hline
\end{tabular}

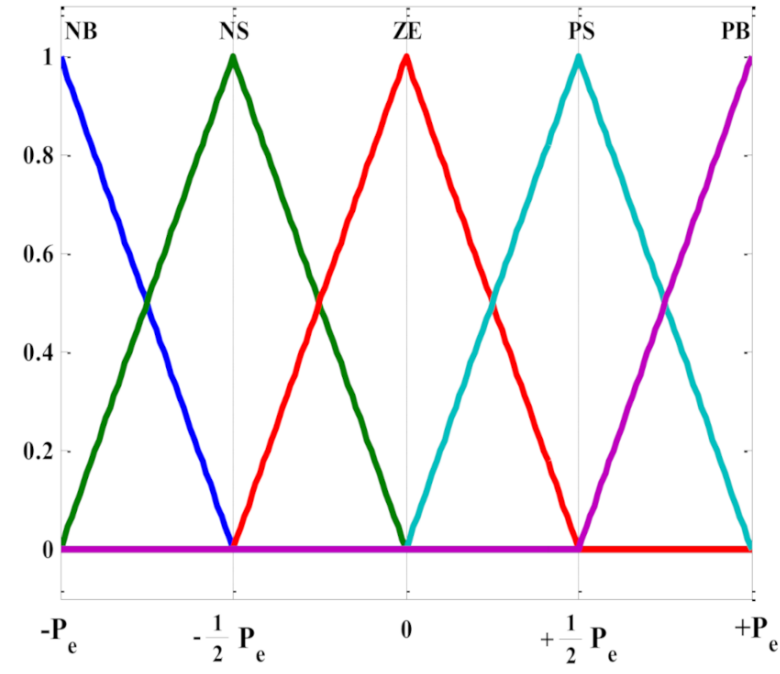

(a)

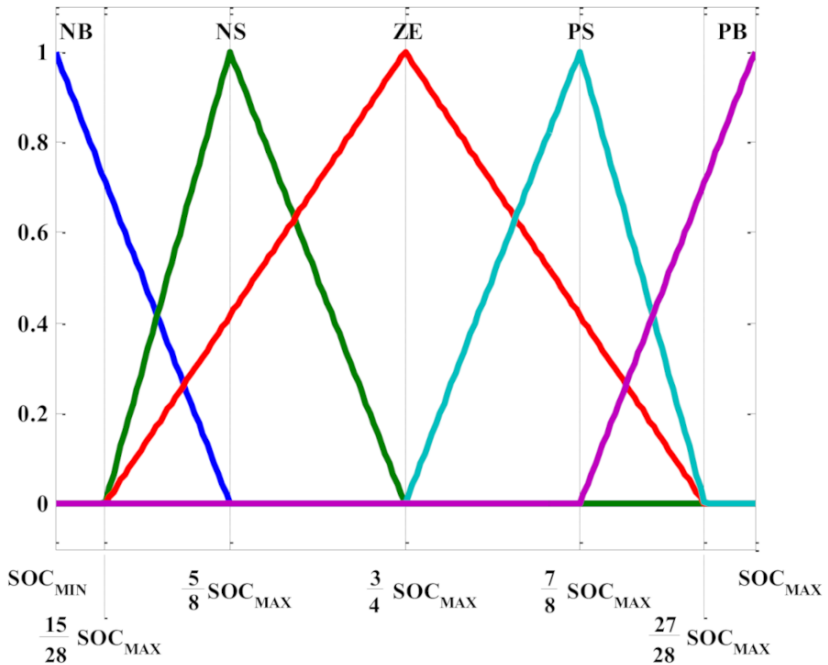

(b)

Figure 4. Cont. 


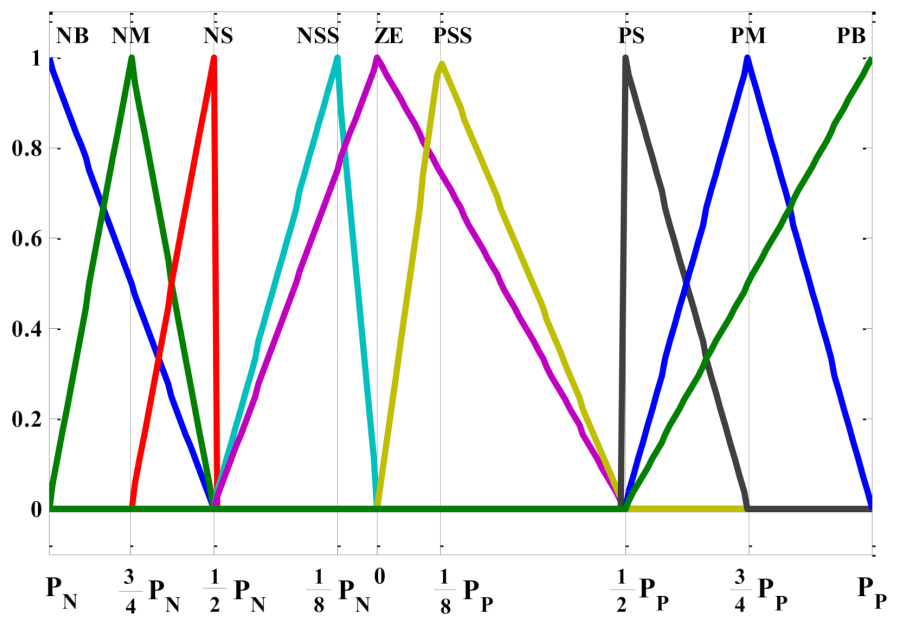

(c)

Figure 4. Fuzzy controller membership functions (MF): (a) Power forecast error, (b) battery state-of-charge (SOC), and (c) fuzzy logic control (FLC) output [45]. (C2016 IEEE, Reprinted, with permission, from Arcos-Aviles D, Guinjoan F, Marietta MP, Pascual J, Marroyo L, Sanchis P. Energy management strategy for a grid-tied residential microgrid based on Fuzzy Logic and power forecasting. IECON 2016-42nd Annu. Conf. IEEE Ind. Electron. Soc., Florence, Italy: IEEE; 2016, pp. 4103-4108.

\section{Optimization Function}

\subsection{Fitness Function}

Since the main objective of the EMS is to smooth the MG power profile by managing the energy balance between renewable energy sources, electric loads, energy storage systems, and the main electrical grid, a set of six quality criteria, which quantify the effectiveness of energy management, is defined according to [20,21,25,26,40-42], as follows:

$$
\begin{gathered}
P_{G, M A X}=\max \left(P_{G R I D}\right) \\
P_{G, M I N}=\min \left(P_{G R I D}\right) \\
M P D=\max \left(\left|\dot{P}_{G R I D}\right|\right) \\
A P D=\frac{1}{M} \sum_{n=1}^{M}\left|\dot{P}_{G R I D}(t)\right| \\
\dot{P}_{G R I D}(t)=\left[P_{G R I D}(t)-P_{G R I D}(t-1)\right] / T_{S} \\
P V R=\frac{P_{G, M A X}-P_{G, M I N}}{P_{L G, M A X}-P_{L G, M I N}} \\
P P V=\sqrt{\sum_{f=f_{i}}^{f_{f}}\left(P_{G R I D, f}\right)^{2}} / P_{D C}
\end{gathered}
$$

where $P_{G, M A X}$ and $P_{G, M I N}$ are the maximum and minimum power of the grid power profile $\left(P_{G R I D}\right) ; M P D$ (maximum power derivative) is the maximum grid power profile ramp-rate $\left(\dot{P}_{G R I D}\right)$ in one year; APD (average power derivative) is the average of the grid power profile ramp-rates in one year, with $M$ being the number of samples in one year; $P V R$ (power variation range) is the grid power profile variation concerning the MG net power; and $P P V$ (power profile variability) gives an idea of the quality of the grid power profile where $P_{G R I D, f}$ is the grid power harmonic at $f$ frequency, and $f_{i}=1.65 \times 10^{-6} \mathrm{~Hz}$ and $f_{f}=5.55 \times 10^{-4} \mathrm{~Hz}$ are the initial and final frequencies defined to evaluate variation periods of above one week or less $[20,21,25,26]$. 
On the other hand, since the FLC tuning procedure can be considered as an optimization process [29], it will require the definition of an optimization (cost) function involving all energy management quality criteria to coherently represent the designer's preferences between objectives in terms of a weighted sum function [46]. This function is defined according to [40], and it is normalized in terms of the reference energy management quality criteria obtained from a previous study where a heuristic-based optimization procedure is applied [43]. From this perspective, the optimization function is defined as follows:

$$
\begin{gathered}
\text { fitness }=w \cdot F_{1}+(w-1) \cdot F_{2} \\
F_{1}=\left(\frac{P_{G, M A X}}{P_{G, M A X}^{R E F}}+\frac{P_{G, M I N}}{P_{G, M I N}^{R E F}}+\frac{M P D}{M P D_{R E F}}\right) \\
F_{2}=\left(\frac{A P D}{A P D_{R E F}}+\frac{P V R}{P V R_{R E F}}+\frac{P P V}{P P V_{R E F}}\right)
\end{gathered}
$$

where $w \geq 1$ is a fixed real number that balances the designer's preference between $F_{1}$ and $F_{2}$, prioritizing one of them during the iterative optimization process [40].

\subsection{Optimization Matrix and Search Space}

The optimization matrix comprises the variables to be optimized. Its dimension is $n \mathrm{x}$ $d$, where $n$ represents the maximum number of agents selected for optimization, i.e., nest for CS, particles for PSO and individuals or population for DE algorithm, and $d$ refers to the total of variables (i.e., size of the dimensional problem). The search space (SS) refers to the domain of the function to be optimized.

The optimization matrix for PSO and DE algorithms is defined in (15). It includes the FLC parameters, such as MFs of inputs $\left(P_{E}^{3 H *}\right.$ and $\left.S O C\right)$ and output $\left(P_{F L C}\right)$, the output universe of discourse $x_{k(-)(+)}$, and the rule base $(R B)$.

$$
x=\left[\begin{array}{c}
x_{1 P E}, x_{1 S O C}, x_{1 P F L C}, x_{1 k(-)(+)}, x_{1 R B} \\
\vdots \\
x_{n P E}, x_{n S O C}, x_{n P F L C}, x_{n k(-)(+)}, x_{n R B}
\end{array}\right]
$$

Table 2 presents the number of variables to be optimized for each parameter, which gives a total of 72 (i.e., $\mathrm{d}=72$ ). In short, both inputs comprise five fuzzy subsets and 11 variables (i.e., three variables for MFs NS, ZE, and PS, and one variable for MFs NB and $\mathrm{PB}$ ). The FLC output comprises 9 fuzzy subsets and 23 variables (i.e., three variables for MFs NM, NS, NSS, ZE, PSS, PS, and PM, and one variable for MFs NB and PB). The FLC rule base comprises 25 rules, thus, 25 variables. Finally, this study considers two variables to define the universe of discourse of the FLC output. Note that this study assumes a fixed universe of discourse for input variables.

Table 2. Number of variables for each fuzzy logic control (FLC) parameter.

\begin{tabular}{cc}
\hline Parameter & Number of Variables \\
\hline Membership functions (MF) for the input $P_{E}^{3 H *}$ & 11 \\
MFs for the input $S O C$ & 11 \\
MFs for the output $P_{F L C}$ & 23 \\
$x_{k(-)(+)}$ & 2 \\
Rule base & 25 \\
Total $(d)$ & 72 \\
\hline
\end{tabular}

Finally, the SS limits are defined based on previous studies [40,41]. The SS of each FLC parameter is presented below. 


$$
\begin{gathered}
x_{P_{E}}=\left\{x_{P_{E}} \in S S_{x_{P_{E}}} \mid-6 \leq x_{P_{E}} \leq 6\right\} \\
x_{S O C}=\left\{x_{S O C} \in S S_{x_{S O C}} \mid 50 \leq x_{S O C} \leq 100\right\} \\
x_{k_{(-)(+)}}=\left\{x_{k_{(-)(+)}} \in S S_{x_{k_{(-)(+)}}} \mid 0 \leq x_{k_{(-)(+)}} \leq 10\right\} \\
x_{P_{F L C}}=\left\{x_{P_{F L C}} \in S S_{\left.x_{P_{F L C}} \mid k_{(-)} \leq x_{P_{F L C}} \leq k_{(+)}\right\}}\right\} \\
x_{R B}=\left\{x_{R B} \in S S_{x_{R B}} \mid 1 \leq x_{R B} \leq 9\right\}
\end{gathered}
$$

\section{Particle Swarm Optimization Algorithm}

PSO is a stochastic technique for the optimization of nonlinear continuous functions designed by Kennedy and Eberhart in 1995 [47]. The operation of this particular metaheuristic is based on the ideal behavior of bird flocks when they look for food. One of the advantages of the PSO algorithm is its rapid convergence without the need for complex calculations when it is compared to other metaheuristic algorithms, such as genetic algorithm and CS, among others.

In the PSO algorithm, the particle swarm has the position $(x)$ and velocity $(v)$ matrices of $i \times j$ dimension within a search space $S S$. Note that it is necessary to add an extra column in the matrix $x$ to record the result of the fitness function $f_{i t}$, as follows:

$$
\begin{gathered}
v=\left[\begin{array}{ccc}
v_{11} & \cdots & v_{1 j} \\
\vdots & \ddots & \vdots \\
v_{i 1} & \cdots & v_{i j}
\end{array}\right] \\
x=\left[\begin{array}{cccc|}
x_{11} & \cdots & x_{1 j} & \text { fit } \\
\vdots & \ddots & \vdots & \vdots \\
x_{i 1} & \cdots & x_{i j} & f_{i t}
\end{array}\right]
\end{gathered}
$$

The velocity and position of each particle are given by (23) and (24), respectively, as follows:

$$
\begin{gathered}
v_{i}(k+1)=w(k) v_{i}(k)+R_{1} C_{1}\left[P_{\text {best }}(k)-x_{i}(k)\right]+R_{2} C_{2}\left[G_{\text {best }}(k)-x_{i}(k)\right] \\
x_{i}(k+1)=x_{i}(k)+v_{i}(k+1)
\end{gathered}
$$

where $v_{i}(k+1)$ and $v_{i}(k)$ are the new and current particles velocities, respectively; $x_{i}(k+1)$ and $x_{i}(k)$ are the positions of the new and current particles, respectively; $w(k)$ is the inertia weight; $C_{1}$ and $C_{2}$ are acceleration constants, which determine the swarm behavior; $R_{1}$ and $R_{2}$ are random numbers within the range [0,1] [31]; $P_{\text {best }}$ is a matrix defined by (25), which records the personal best position of each particle; and, $G_{\text {best }}$ is a vector, defined by (26), which records the best global position of all swarm. Similarly, matrix (25) and vector (26) add a column vector with the result of the fitness function.

$$
\begin{gathered}
P_{\text {best }}=\left[\begin{array}{ccc|c}
P_{\text {best }_{11}} & \cdots & P_{\text {best }_{1 j}} & \text { fit }_{\text {Pbest }_{1}} \\
\vdots & \ddots & \vdots & \vdots \\
P_{\text {best }_{11}} & \cdots & P_{\text {best }_{i j}} & \text { fit }_{\text {Pbest }_{i}}
\end{array}\right] \\
G_{\text {best }}=\left[\begin{array}{llll}
G_{\text {best }_{11}} & \cdots & G_{\text {best }_{1 j}} & \text { fit }_{\text {Gbest }}
\end{array}\right]
\end{gathered}
$$

For each particle, its fitness $x_{i}(k+1)$ is compared with its best-recorded position in $P_{\text {best }}$. If the new fitness is less than the best value seen so far, $P_{\text {best }}$ is updated with $x_{i}(k+1)$. 
After that, the lowest value of fitness in $P_{\text {best }}$ is found and compared to $G_{b e s t}$. If the fitness of the best particle is lower than the best global position, $G_{b e s t}$ is updated by $P_{\text {best }}$.

The inertia weight of $v_{i}(k)$ is given by (27), which value decreases at each iteration. A maximum and minimum weight of $w_{\max }=0.9$ and $w_{\min }=0.4$, respectively, are selected according to [31], as follows:

$$
w(k)=\frac{w_{\min }-w_{\max }}{k_{\max }-1}(k-1)+w_{\max }
$$

The pseudo-code to implement the PSO algorithm applied for adjusting the FLC parameters is presented in Algorithm 1. Note that $k_{\max }$ represents the number of iterations $\left(k_{\max }=300\right)$ whereas, according to [48], the values of accelerations constants $C_{1}$ and $C_{2}$ are set to the same value $\left(C_{1}=C_{2}=2\right)$

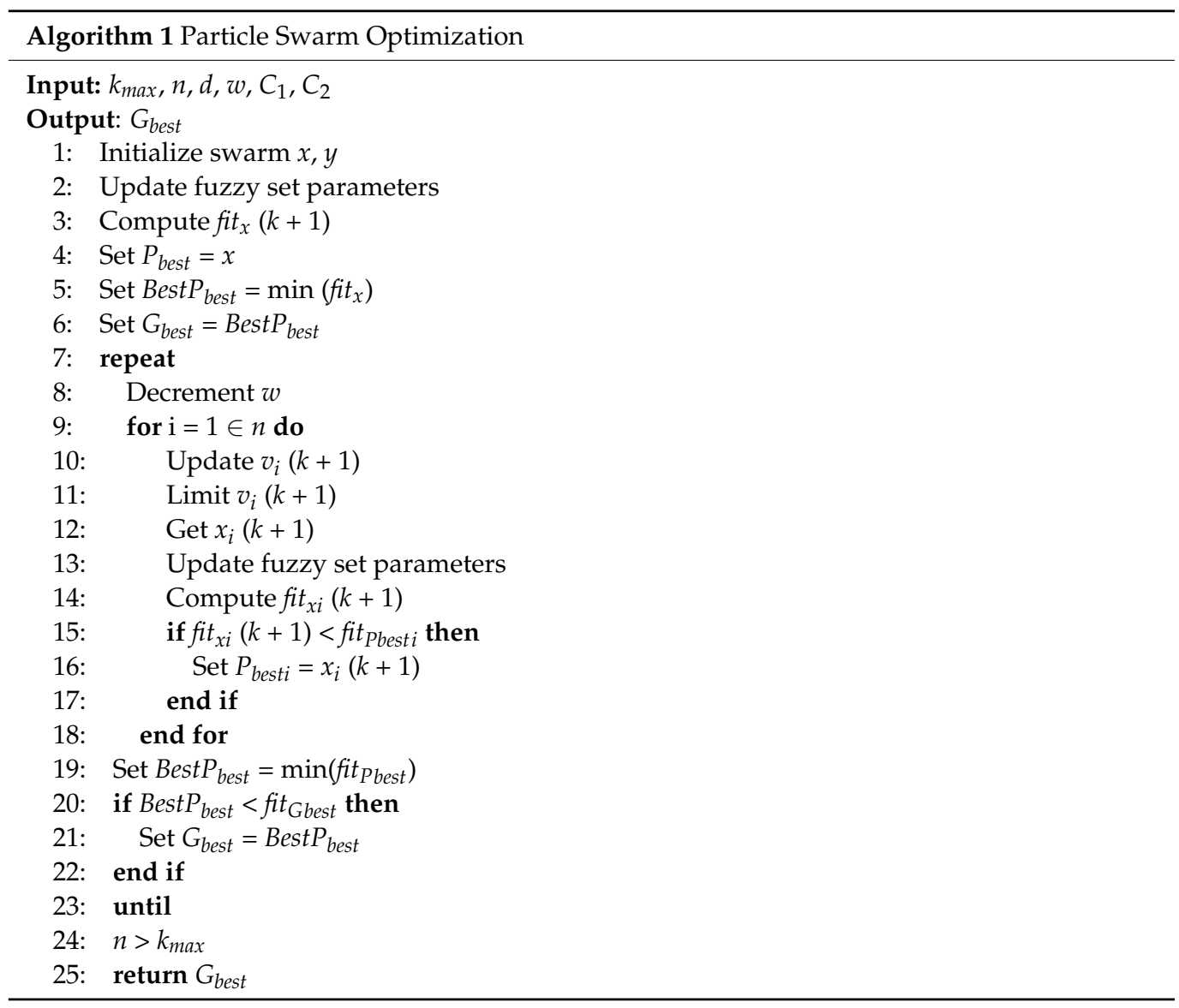

\section{Differential Evolution Algorithm}

The DE algorithm is a nature-inspired metaheuristic algorithm proposed by Rainer Storn and Kenneth Price in 1995 [49]. It is an evolutionary algorithm, which is based on the natural and genetic selection of populations. In general, the DE algorithm uses mutation, crossing, and selection operators to generate new individuals. The main characteristic of the $\mathrm{DE}$ algorithm is the use of a minimum number of parameters, such as the scale factor, $F$, crossover rate, $C_{r}$, the size of the dimensional problem, $d$, and the number of individuals or population, $n$, [31].

Initially, the DE algorithm performs a random selection of a population of $n$ vectors, with uniform distribution, which will cover the entire search space [49]. This selection delivers the initial vector $x_{i}$, which is used to carry out the mutation, crossover, and selection processes. 


$$
x_{i}^{t}=\left(x_{1, i}^{t}, x_{2, i}^{t}, \cdots, x_{d, i}^{t}\right)
$$

where $i=1,2, \ldots, n$ for each solution $x_{i}$ in any generation $t$.

The DE algorithm attempts to replicate the biological behavior of evolution in a computer program. The mutation in the evolution of an individual consists of the random variation of one of its genes. The DE algorithm takes this behavior as a reference. For each target vector $x_{i}$, a mutation vector, $v_{i}$, is generated according to the following mutation scheme:

$$
v_{i}^{t+1}=x_{p}^{t}+F \cdot\left(x_{q}^{t}-x_{r}^{t}\right)
$$

where $x_{p}, x_{q}$, and $x_{r}$ are the target vectors at $t$, which are created from three randomly chosen individuals in the population to cause a vector, in any of its values, to vary randomly. Note that the scale factor, $F$, is a real value between $[0, \infty)$, which is used to scale the differential variation of the scanning vector $\left(x_{q}-x_{r}\right)$. This study considers a scale factor between $[0,1]$, according to [50].

Then, after a random set of vectors have been selected, the crossover operation is carried out. In addition, a mutation operation is also applied to the recombined vector in order to generate the final population. This process is controlled by the parameter $C_{r} \in[0,1]$, which controls the crossover rate [51]. This study uses a binomial crossover scheme, which performs a crossover on each of the variable components. The test vector $u$ is obtained as follows:

$$
u_{j . i}^{t+1}=\left\{\begin{array}{c}
v_{j, i}^{t+1}, \text { ifr } r_{j} \leq C_{r} \wedge j=J r \\
x_{j, i}^{t}, \text { if } r_{j}>C_{r} \vee j \neq J r
\end{array}\right.
$$

where $j=1,2, \ldots, d, r_{j} \in(0,1), C_{r} \in[0,1]$ is a user-defined constant, and $J r=1, \ldots, d$ is a randomly index, which is chosen to ensure that $u_{j, i}^{t+1}$ receives at least one component of $v_{j, i}^{t+1}$.

Finally, selection in evolution refers to choosing which individuals pass to the next generation. After the mutation and crossover stages, in which all $n$ vectors served as a target vector, for selection, the fitness value of each test vector $f\left(u_{i}^{t+1}\right)$ is compared with its corresponding target vector $f\left(x_{i}^{t}\right)$ in the current population [31]. Then, the selection of the vectors that will be preserved for the next generation is the one who has the best performance function value [49], i.e.,

$$
x_{i}^{t+1}=\left\{\begin{array}{l}
u_{i}^{t+1}, \text { iff }\left(u_{i}^{t+1}\right) \leq f\left(x_{i}^{t}\right) \\
x_{i}^{t}, \text { otherwise }
\end{array}\right.
$$

The DE algorithm pseudo-code used to find the best population for adjusting the FLC parameters of the EMS is presented in Algorithm 2. Note that this study considers $F=0.7$, $C_{r}=0.9$, and $n=25$ according to $[31,50,52]$.

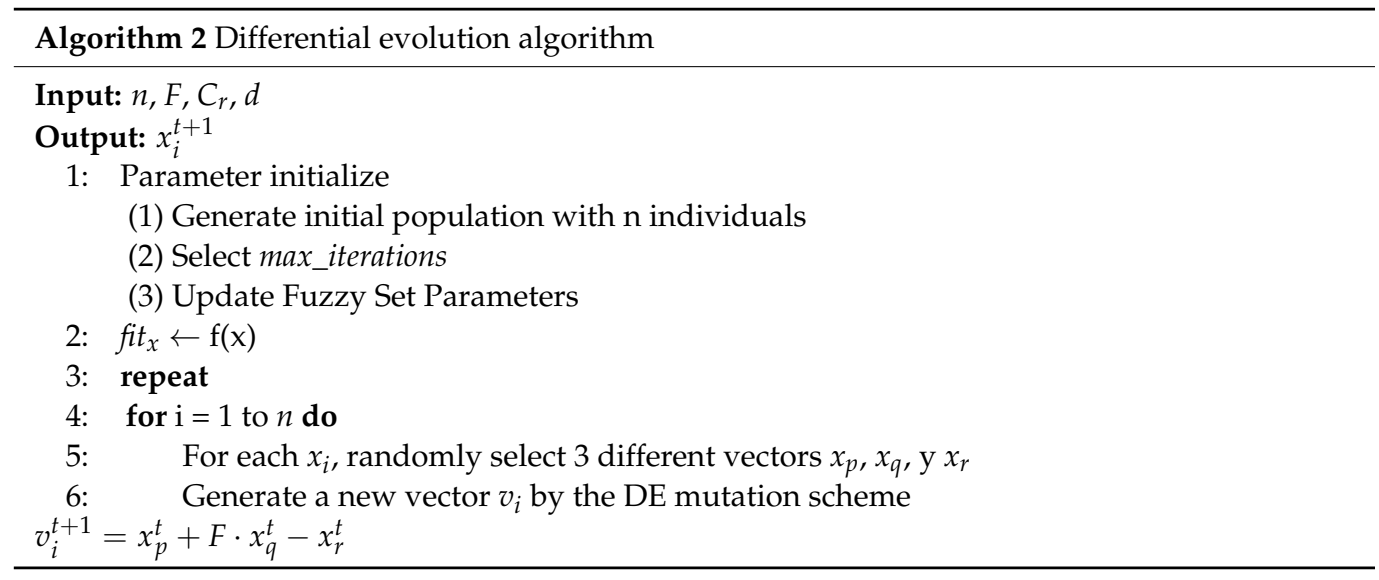




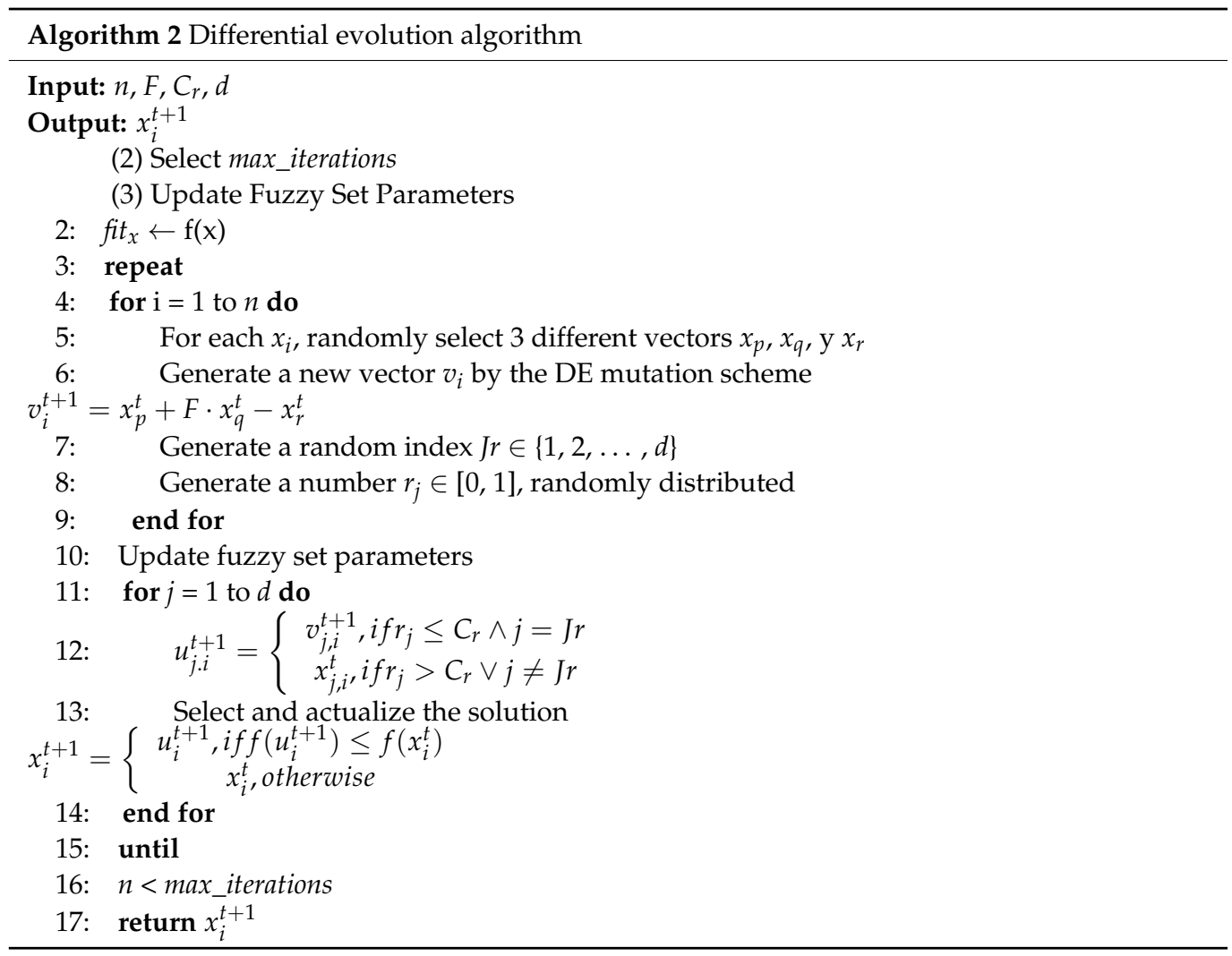

\section{Comparison Results}

\subsection{Fuzzy Logic Control Parameters Comparison}

The result of adjusting the FLC controller parameters through the PSO and DE algorithms is presented below. In addition, the results achieved by the CS algorithm $[40,41]$ are included for comparison purposes. The FLC parameters obtained through the CS, PSO, and DE algorithms are presented in Figures 5-7, respectively, where each MF, for inputs variables, is superposed to the respective achieved by heuristic method (HM). In addition, the resulting rule base achieved by each algorithm is presented in Tables 3-5.

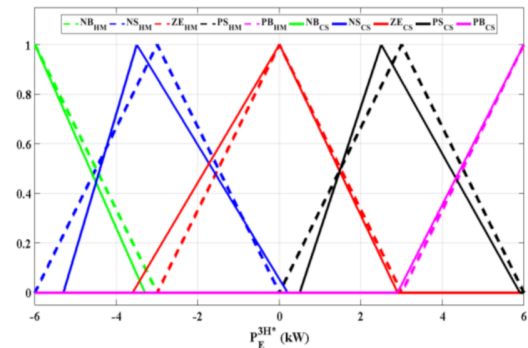

(a)

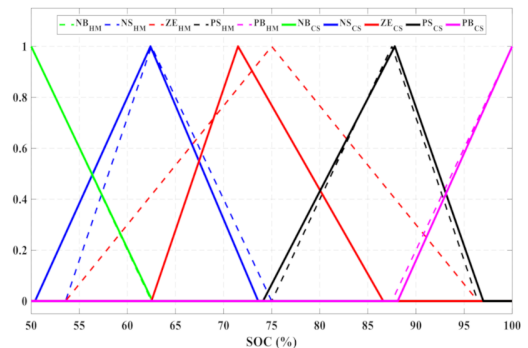

(b)

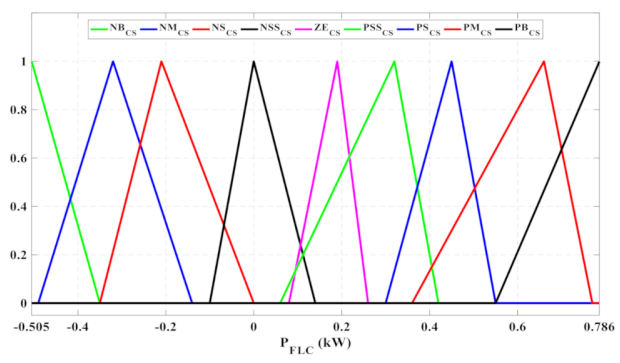

(c)

Figure 5. Resulting MFs through Cuckoo search (CS) algorithm (a) input $P_{E}^{3 H *},(\mathbf{b})$ input $S O C$, and (c) output $P_{F L C}$. 


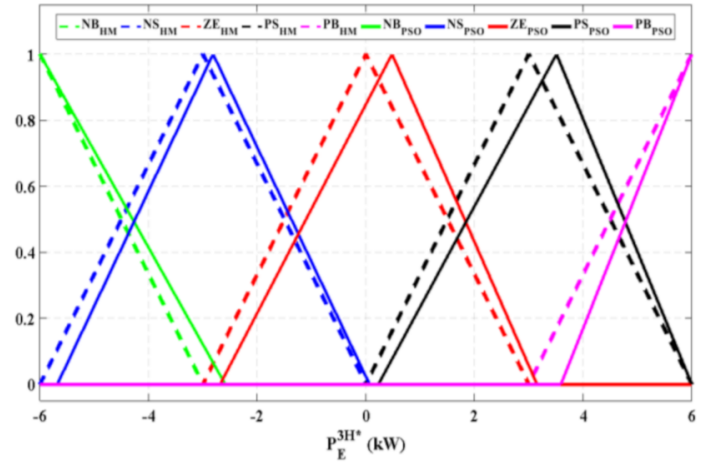

(a)

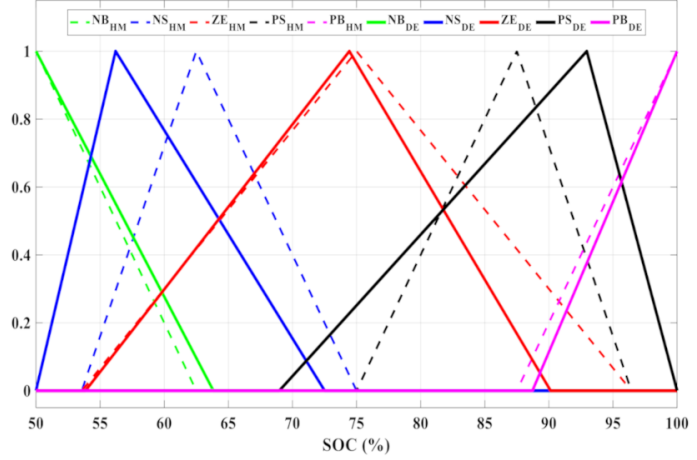

(b)

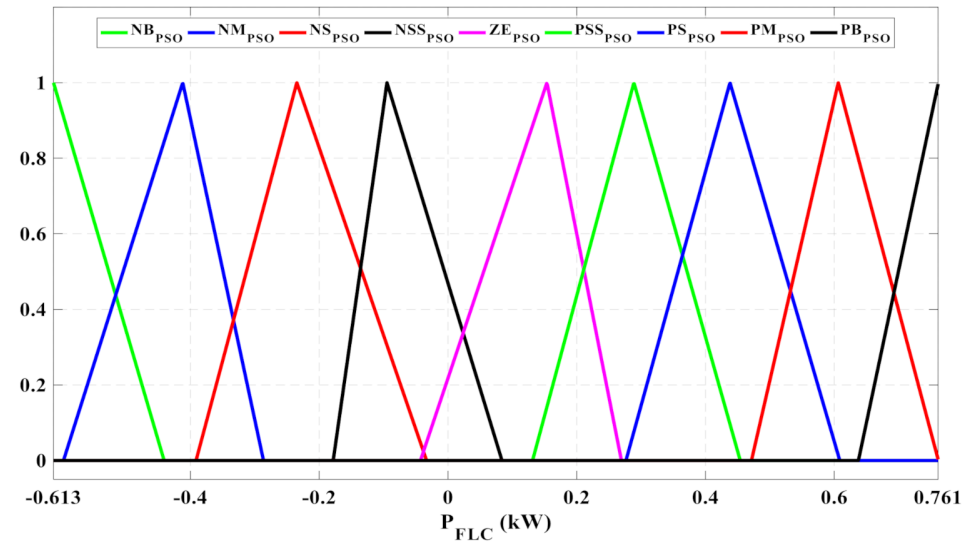

(c)

Figure 6. Resulting MFs through Particle Swarm Optimization (PSO) algorithm (a) input $P_{E}^{3 H *}$, (b) input $S O C$, and (c) output $P_{F L C}$.

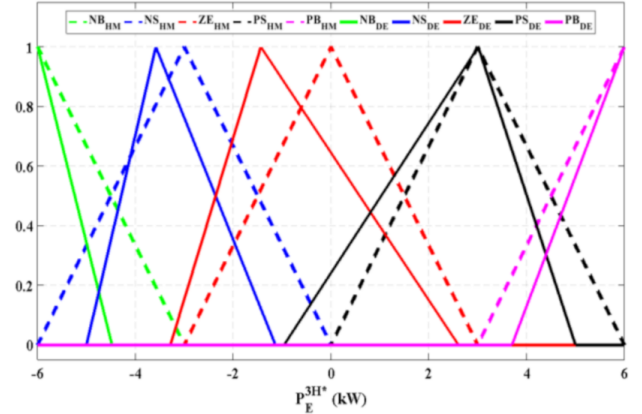

(a)

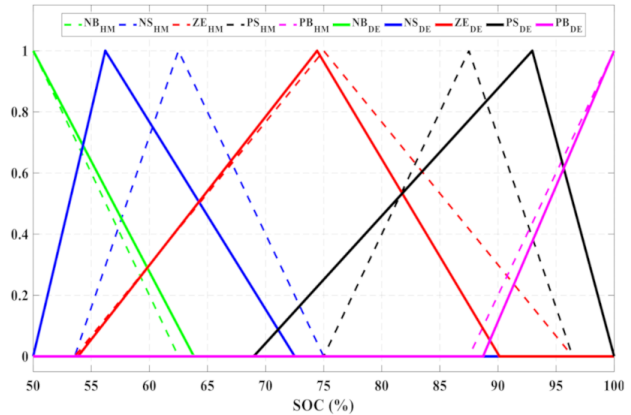

(b)

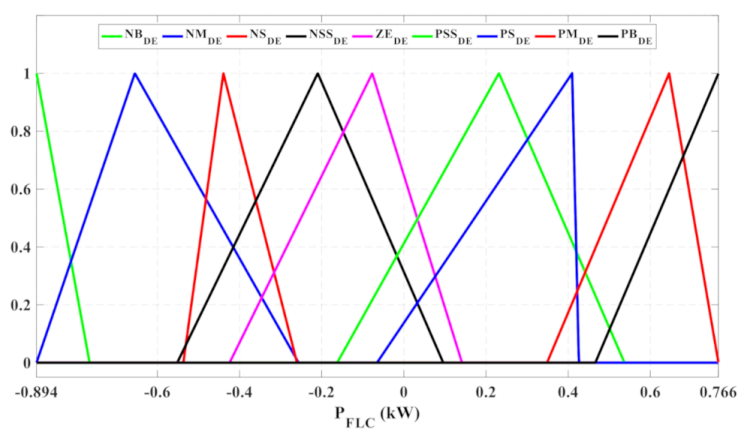

(c)

Figure 7. Resulting MFs through Differential Evolution (DE) algorithm (a) input $P_{E}^{3 H *},(\mathbf{b})$ input $S O C$, and (c) output $P_{F L C}$. 
Table 3. Optimized rule base through Cuckoo Search (CS) algorithm $[40,41]$.

\begin{tabular}{ccccccc}
\hline \multicolumn{3}{c}{$\boldsymbol{P}_{\text {FLC }}(n)$} & & \multicolumn{5}{c}{$P_{E}^{*}(n)$} \\
\cline { 3 - 7 } & & NB & NS & ZE & PS & PB \\
\hline \multirow{4}{*}{$\operatorname{soC}(n)$} & NB & ZE & ZE & PS & PM & PB \\
& NS & NSS & ZE & PSS & PS & PB \\
& ZE & NS & NSS & ZE & PSS & PS \\
& PS & NM & NS & NSS & ZE & PSS \\
& PB & NB & NM & NS & NS & ZE \\
\hline
\end{tabular}

Table 4. Optimized rule base through Particle Swarm Optimization (PSO).

\begin{tabular}{ccccccc}
\hline \multicolumn{3}{c}{$\boldsymbol{P}_{\boldsymbol{F L C}}(n)$} & \multicolumn{7}{c}{$P_{E}^{*}(n)$} & PS & PB \\
\cline { 3 - 7 } & & NB & NS & ZE & PS & PB \\
& NB & ZE & PSS & PS & PS & PM \\
\multirow{4}{*}{$S O C(n)$} & NS & ZE & ZE & PSS & PS & PS \\
& ZE & NS & NSS & ZE & PSS & PSS \\
& PS & NM & NS & NSS & ZE & ZE \\
\hline
\end{tabular}

Table 5. Optimized rule base through Differential Evolution (DE) algorithm.

\begin{tabular}{ccccccc}
\hline \multicolumn{3}{c}{$\boldsymbol{P}_{\text {FLC }}(n)$} & & \multicolumn{5}{c}{$P_{E}^{*}(n)$} & PS & PB \\
\cline { 3 - 7 } & & NB & NS & ZE & PS & PB \\
& NB & PS & PB & PS & PB & PB \\
\multirow{4}{*}{ SOC $(n)$} & NS & ZE & PM & PSS & PSS & PS \\
& ZE & NSS & PSS & PSS & ZE & NSS \\
& PS & NSS & PSS & NS & ZE & NB \\
\hline
\end{tabular}

\subsection{Energy Management System Performance Comparison}

This section presents the results achieved by the EMS after the FLC controller parameter setting process through the nature-inspired algorithms described above. Furthermore, a comparison is made with the results obtained through the EMS described in [43] where the parameters of its FLC block are adjusted using a heuristic process and also with the results obtained by the EMS presented in $[40,41]$ where the adjustment of the FLC parameters is made through the CS algorithm.

The comparison is made over the same FLC parameters optimization problem in terms of the quality of the solutions and the computation time. Therefore, the same initial set of random solutions (i.e., initial population), the optimization function defined in Section 3, and the standard algorithm's parameters [31] have been implemented.

A weighting factor of $w=2$ is used in the optimization function defined in Section 3 to prioritize the minimization of $P_{G, M A X}, P_{G, M I N}$, and $M P D$ over $A P D, P P V$, and $P V R$ since the main objective of the EMS is to smooth the power profile exchanged with the grid (i.e., minimizing grid power ramp-rates, power peaks [40]. Numerical simulations, using Matlab $^{\circledR}$ (MathWorks, Natick, MA, USA), are carried out in an INTEL ${ }^{\circledR}$ Core $^{\mathrm{TM}}-\mathrm{i} 76500 \mathrm{U}$ CPU $2.50 \mathrm{GHz}$ computer, where the three algorithms are executed under the same initial conditions to solve 300 iterations.

For the case study, the convergence of the optimization function and the number of iterations required by the algorithms under analysis to converge to its feasible optimum is shown in Figure 8. 


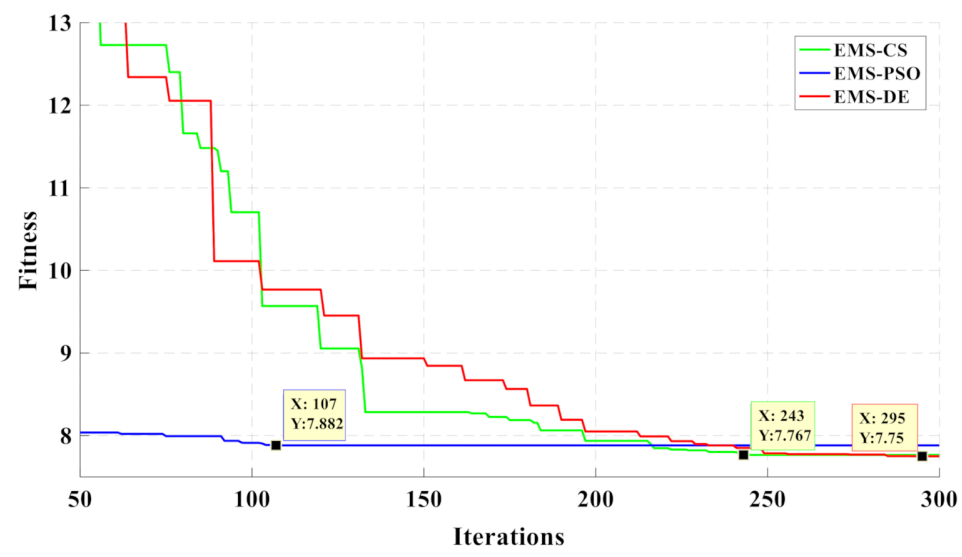

Figure 8. Convergence chart.

As can be seen in Figure 8, the CS and DE algorithms perform similarly in terms of convergence rate. However, the obtained solution through $\mathrm{DE}$ is slightly better than the one achieved by the CS in terms of the solution quality since the optimization function's value for $\mathrm{DE}$ is lower than the CS value, as shown in Table 6.

Table 6. Fitness comparison.

\begin{tabular}{cc}
\hline EMS Strategy & Fitness \\
\hline EMS [43] & 9 \\
CS optimized EMS [40] & 7.76 \\
PSO optimized EMS & 7.88 \\
DE optimized EMS & 7.75 \\
\hline
\end{tabular}

On the other hand, an analysis of the convergence time is shown in Table 7, where the population length represents the number of population agents, such as the CS-nest, PSO-particles, DE-candidate solutions; the time per iteration is the time that takes to analyze each agent in one iteration; the convergence iteration is the iteration in which the algorithm converges; and the convergence time represents the total execution time until the convergence iteration is reached. In short, the PSO algorithm presents a less convergence time than the CS and DE algorithms for the case under study.

Table 7. Convergence time analysis for CS, PSO, and DE algorithms.

\begin{tabular}{ccccc}
\hline Algorithm & $\begin{array}{c}\text { Population } \\
\text { Length }\end{array}$ & $\begin{array}{c}\text { Time per } \\
\text { Iteration (min) }\end{array}$ & Iterations & Conv. Time (h) \\
\hline CS & 25 & 16.1 & 243 & 65.21 \\
PSO & 25 & 16.1 & 107 & 28.71 \\
DE & 25 & 16.1 & 295 & 79.16 \\
\hline
\end{tabular}

Despite that PSO presents better behavior than the CS and DE algorithms in terms of the convergence rate, the obtained solutions by the CS and DE algorithms are slightly better than the solution achieved by the PSO algorithm for the case under study. In this regard, Table 8 presents the results of evaluating the power profile that the MG exchanges with the utility network achieved by the EMSs under analysis. In addition, Figure 9 shows the grid power profile for each EMS design, where it can be seen that all the designs meet the objective of smoothing the power profile exchanged with the main grid (i.e., minimizing power peaks and fluctuations). Finally, Figure 10 shows the grid power profile ramp-rates, along one year, achieved by the analyzed EMSs. As can be seen, the fuzzy logic-based EMS obtained through nature-inspired algorithms present a considerable reduction in the power ramp-rates of the grid power profile, which facilitates the control of grid operators and the penetration of RES into the mains. 
Table 8. Grid power profile quality criteria comparison.

\begin{tabular}{ccccccc}
\hline EMS Strategy & $\begin{array}{c}\boldsymbol{P}_{G, M A X} \\
\mathbf{( k W )}\end{array}$ & $\begin{array}{c}\boldsymbol{P}_{G, M I N} \\
\mathbf{( k W )}\end{array}$ & $\begin{array}{c}\text { MPD } \\
\mathbf{( W / h )}\end{array}$ & $\begin{array}{c}\text { APD } \\
(\mathbf{W} / \mathbf{h})\end{array}$ & $\boldsymbol{P P V}$ & $\boldsymbol{P V R}$ \\
\hline EMS-FC [43] & 2.56 & -1.89 & 846 & 75 & 1.26 & 0.34 \\
EMS-CS [40] & 2.51 & -1.66 & 469 & 75 & 1.25 & 0.32 \\
EMS-PSO & 2.51 & -1.71 & 489 & 76 & 1.26 & 0.32 \\
EMS-DE & 2.50 & -1.60 & 487 & 74 & 1.29 & 0.32 \\
\hline
\end{tabular}

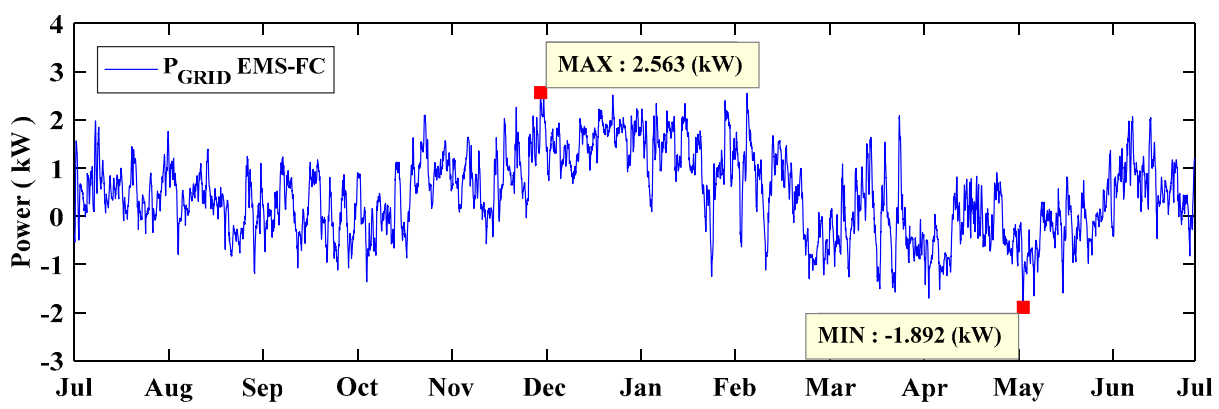

(a)

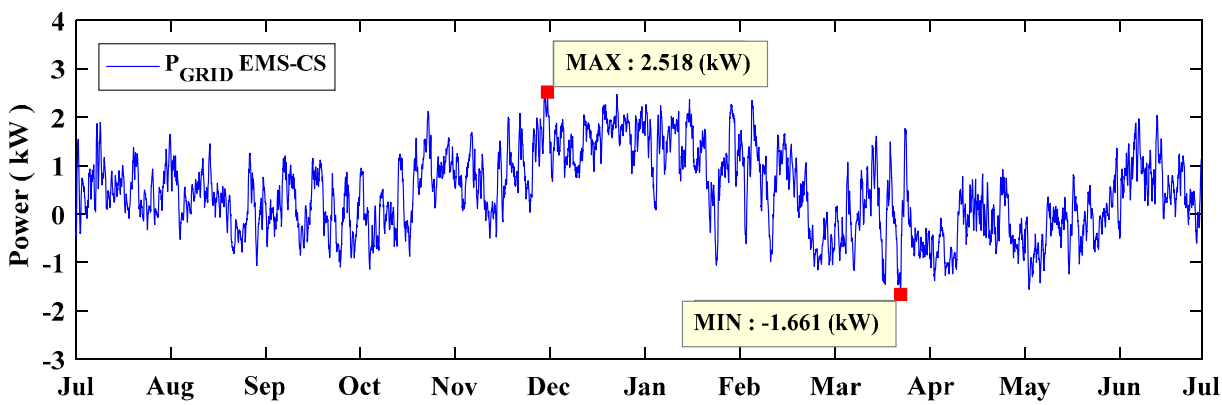

(b)

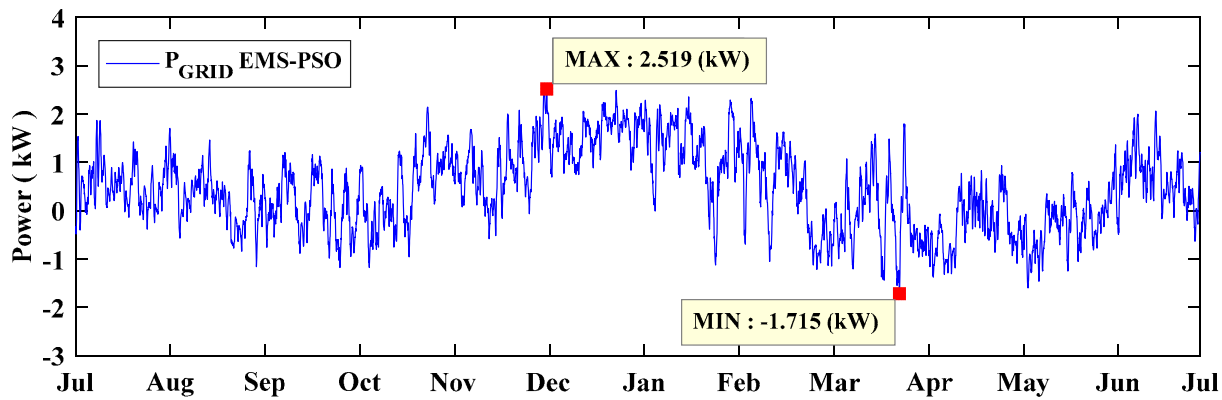

(c)

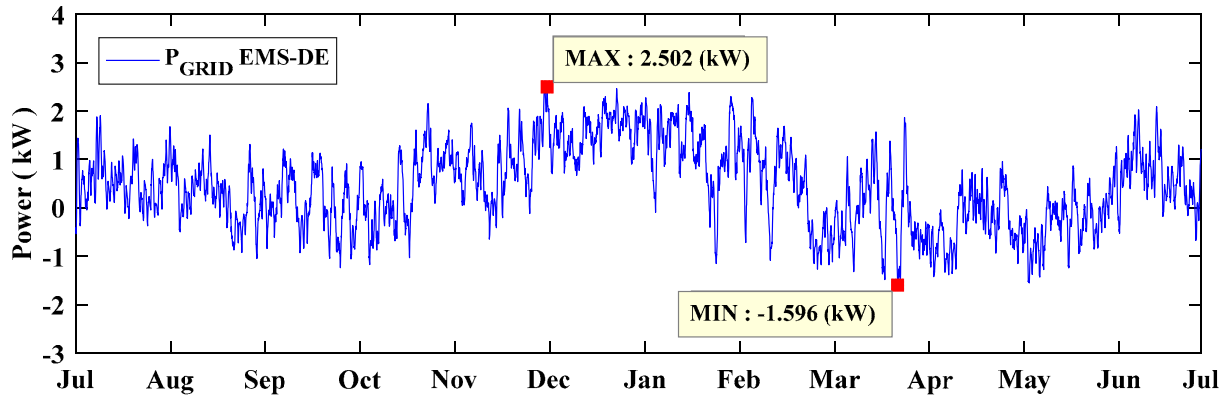

(d)

Figure 9. Grid power profile comparison for different EMS designs (a) heuristic, (b) CS algorithm, (c) PSO, and (d) DE algorithm. 


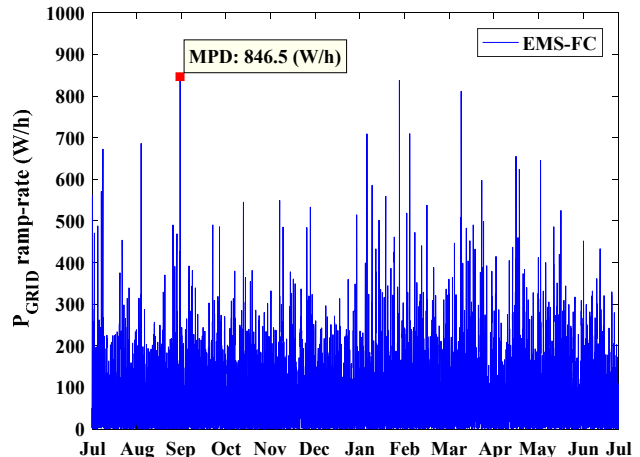

(a)

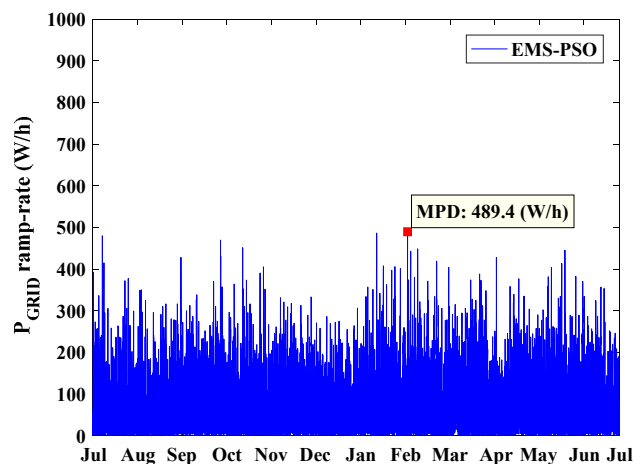

(c)

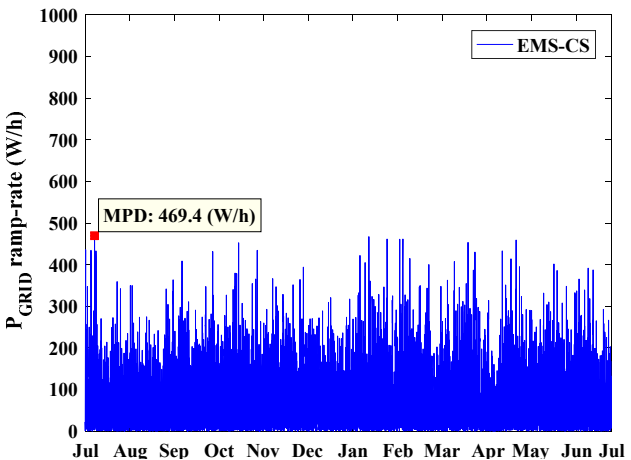

(b)

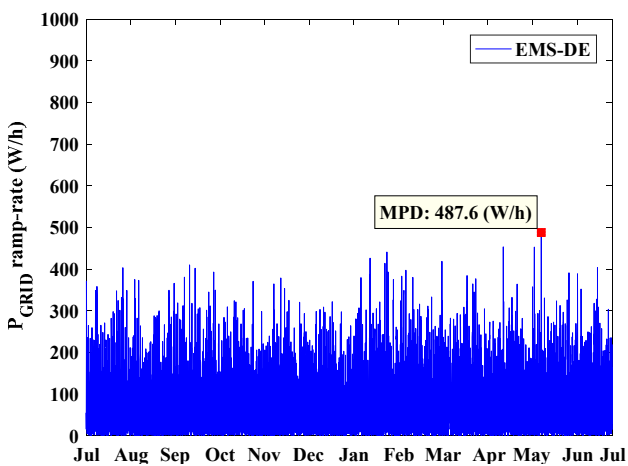

(d)

Figure 10. Grid power ramp-rates (a) EMS-FC, (b) EMS-CS, (c) EMS-PSO, and (d) EMS-DE.

\section{Conclusions}

This paper has addressed the tuning of parameters using the nature-inspired PSO and DE algorithms of an FLC that is part of the EMS of a residential grid-connected electro-thermal microgrid. The FLC-based EMS has been designed to smooth the power profile exchanged with the grid. Numerical simulations have allowed the performance comparison between PSO-tuned and DE-tuned EMSs as well as with heuristically tuned and CS-tuned EMSs presented in previous works. In the adjustment process, the algorithms perform the optimization of 72 variables corresponding to the MF mapping of inputs and the output as well as the FLC rule base. The results have shown that all the designs are capable of meeting the objective pursued by the EMS, obtaining a smooth grid power profile, and the evolution of the battery SOC within the permitted ranges. Moreover, it has been shown that all EMSs designs resulting from a tuning process based on PSO, DE, and CS nature-inspired algorithms have obtained a reduction in the maximum grid power ramp-rates (MPD) of over $40 \%$ when being compared to a fuzzy-based EMS where the adjustment of the FLC uses a heuristic approach. In addition, simulation results have revealed that the PSO algorithm performs better than CS and DE algorithms regarding the convergence time. Finally, the quality criteria comparison have shown that the CS algorithm has achieved an improved solution in terms of the MPD and PPV quality criteria, whereas the DE algorithm presents a better behavior concerning the $P_{G, M A X}, P_{G, M I N}$, and $A P D$ criteria.

Therefore, this study has shown that the different nature-inspired optimization algorithms present similar results when it comes to improving FLC-based EMSs. However, convergence time is a critical parameter that should be considered in any deployment, especially if a real-time implementation is required. Furthermore, the set of input parameters needed for each algorithm must be understood to provide stability and robustness to the optimization task. Finally, these nature-inspired optimization algorithms are able to optimize the FLC rule base and the MF mapping simultaneously, using a single cost function for both activities. 
Future work will focus on the design of a real-time adaptive fuzzy-based energy management system. This new design will update the fuzzy logic control parameters at the same time as the forecast variables, which could improve the EMS efficiency.

Author Contributions: Conceptualization, D.A.-A., D.P. (Diego Pacheco), D.P. (Daniela Pereira) and E.V.C.; data curation D.P. (Diego Pacheco), D.P. (Daniela Pereira) and G.G.-G.; formal analysis D.A.-A., E.V.C., F.G., P.A., A.I. and W.M.; investigation D.P. (Diego Pacheco), D.P. (Daniela Pereira) and D.A.-A.; methodology D.P. (Diego Pacheco), D.P. (Daniela Pereira), D.A.-A., E.V.C. and F.G.; project administration D.A.-A. and W.M.; software D.P. (Diego Pacheco), D.P. (Daniela Pereira) and G.G.-G.; supervision D.A.-A. and E.V.C.; validation D.A.-A. and E.V.C.; visualization P.A. and A.I.; writing-original draft preparation D.A.-A., D.P. (Diego Pacheco), D.P. (Daniela Pereira), G.G.-G., E.V.C., F.G., P.A. and A.I.; writing-review and editing D.A.-A., E.V.C., F.G. and W.M. All authors have read and agreed to the published version of the manuscript.

Funding: This work is part of the projects 2019-PIC-003-CTE and 2020-EXT-007 from the Research Group of Propagation, Electronic Control, and Networking (PROCONET) of Universidad de las Fuerzas Armadas ESPE. This work has been developed with the support of VLIR-UOS and the Belgian Development Cooperation (DGD) under the project EC2020SIN322A101. This work has been partially supported by the Spanish Ministry of Industry and Competitiveness under the grant DPI2017-85404 and PID2019-111443RB-100.

Institutional Review Board Statement: Not applicable.

Informed Consent Statement: Not applicable.

Acknowledgments: A special acknowledgment to the Public University of Navarre (UPNa), Pamplona, Spain, and the INGEPER research group who provided the microgrid data that were used in this work.

Conflicts of Interest: The authors declare no conflict of interest.

\section{References}

1. International Energy Agency. Key World Energy Statistics; International Energy Agency: Paris, France, 2018.

2. International Energy Agency. $\mathrm{CO}_{2}$ Emissions from Fuel Combustion 2018; OECD: Paris, France, 2018.

3. Kanchev, H.; Lu, D.; Colas, F.; Lazarov, V.; Francois, B. Energy Management and Operational Planning of a Microgrid With a PV-Based Active Generator for Smart Grid Applications. IEEE Trans. Ind. Electron. 2011, 58, 4583-4592. [CrossRef]

4. Lasseter, R. MicroGrids. In Proceedings of the IEEE Power Engineering Society Winter Meeting, New York, NY, USA, 27-31 January 2002; pp. 305-308. [CrossRef]

5. Olivares, D.E.; Mehrizi-Sani, A.; Etemadi, A.H.; Canizares, C.A.; Iravani, R.; Kazerani, M.; Hajimiragha, A.H.; Gomis-Bellmunt, O.; Saeedifard, M.; Palma-Behnke, R.; et al. Trends in Microgrid Control. IEEE Trans. Smart Grid 2014, 5, 1905-1919. [CrossRef]

6. Da Silva, I.R.; Rabêlo, R.D.A.; Rodrigues, J.J.; Solic, P.; Carvalho, A. A preference-based demand response mechanism for energy management in a microgrid. J. Clean. Prod. 2020, 255, 120034. [CrossRef]

7. Nge, C.L.; Ranaweera, I.U.; Midtgård, O.-M.; Norum, L. A real-time energy management system for smart grid integrated photovoltaic generation with battery storage. Renew. Energy 2019, 130, 774-785. [CrossRef]

8. Sahoo, S.K.; Sinha, A.K.; Kishore, N.K. Control Techniques in AC, DC, and Hybrid AC-DC Microgrid: A Review. IEEE J. Emerg. Sel. Top. Power Electron. 2017, 6, 738-759. [CrossRef]

9. Nojavan, S.; Pashaei-Didani, H.; Mohammadi, A.; Ahmadi-Nezamabad, H. Energy management concept of AC, DC, and hybrid AC/DC microgrids. In Risk-Based Energy Management; Elsevier: Amsterdam, The Netherlands, 2020; pp. 1-10. [CrossRef]

10. Unamuno, E.; Barrena, J.A. Hybrid ac/dc microgrids-Part I: Review and classification of topologies. Renew. Sustain. Energy Rev. 2015, 52, 1251-1259. [CrossRef]

11. Zia, M.F.; Elbouchikhi, E.; Benbouzid, M. Microgrids energy management systems: A critical review on methods, solutions, and prospects. Appl. Energy 2018, 222, 1033-1055. [CrossRef]

12. Vera, Y.E.G.; Dufo-López, R.; Bernal-Agustín, J.L. Energy Management in Microgrids with Renewable Energy Sources: A Literature Review. Appl. Sci. 2019, 9, 3854. [CrossRef]

13. Vahedipour-Dahraie, M.; Rashidizadeh-Kermani, H.; Anvari-Moghaddam, A.; Guerrero, J.M. Stochastic Risk-Constrained Scheduling of Renewable-Powered Autonomous Microgrids With Demand Response Actions: Reliability and Economic Implications. IEEE Trans. Ind. Appl. 2019, 56, 1882-1895. [CrossRef]

14. Marzband, M.; Alavi, H.; Ghazimirsaeid, S.S.; Uppal, H.; Fernando, T. Optimal energy management system based on stochastic approach for a home Microgrid with integrated responsive load demand and energy storage. Sustain. Cities Soc. 2017, 28, 256-264. [CrossRef] 
15. Korkas, C.D.; Baldi, S.; Michailidis, I.; Kosmatopoulos, E.B. Intelligent energy and thermal comfort management in grid-connected microgrids with heterogeneous occupancy schedule. Appl. Energy 2015, 149, 194-203. [CrossRef]

16. NERSA. Grid Connection Code for Renewable Power Plants (RPPs) Connected to the Electricity Transmission System (TS) or the Distribution System (DS) in South Africa. 2014. Available online: https://www.sseg.org.za/wp-content/uploads/2019/03/ South-African-Grid-Code-Requirements-for-Renewable-Power-Plants-Version-2-8.pdf (accessed on 1 February 2021).

17. Energy Regulatory Commission, Philippine Distribution Code 2016 Edition. Available online: http:/ /www.erc.gov.ph/Files/ Render/media/PhilippineDistributionCode2016Edition.pdf (accessed on 1 February 2021).

18. Australian Energy Market Commission. National Electricity Rules Version 56 Chapter 3: Market Rules, Aust. Energy Mark. 2013; p. 146. Available online: https://www.aemc.gov.au/sites/default/files/content/National-Electricity-Rules-historical-version79.PDF (accessed on 1 February 2021).

19. Zhang, C.; Lin, W.; Ke, D.; Sun, Y. Smoothing Tie-Line Power Fluctuations for Industrial Microgrids by Demand Side Control: An Output Regulation Approach. IEEE Trans. Power Syst. 2019, 34, 3716-3728. [CrossRef]

20. Pascual, J.; Sanchis, P.; Marroyo, L. Implementation and Control of a Residential Electrothermal Microgrid Based on Renewable Energies, a Hybrid Storage System and Demand Side Management. Energies 2014, 7, 210-237. [CrossRef]

21. Pascual, J.; Barricarte, J.; Sanchis, P.; Marroyo, L. Energy management strategy for a renewable-based residential microgrid with generation and demand forecasting. Appl. Energy 2015, 158, 12-25. [CrossRef]

22. Leonori, S.; Martino, A.; Mascioli, F.M.F.; Rizzi, A. Microgrid Energy Management Systems Design by Computational Intelligence Techniques. Appl. Energy 2020, 277, 115524. [CrossRef]

23. Leonori, S.; Paschero, M.; Mascioli, F.M.F.; Rizzi, A. Optimization strategies for Microgrid energy management systems by Genetic Algorithms. Appl. Soft Comput. 2020, 86, 105903. [CrossRef]

24. Avilés, D.A.; Pascual, J.E.S.; Marroyo, L.; Sanchis, P.; Guinjoan, F.; Marietta, M.P. Optimal Fuzzy Logic EMS design for residential grid-connected microgrid with hybrid renewable generation and storage. In Proceedings of the IEEE 24th International Symposium on Industrial Electronics (ISIE), Armacao dos Buzios, Brazil, 3-5 June 2015; pp. 742-747. [CrossRef]

25. Arcos-Aviles, D.; Pascual, J.; Marroyo, L.; Sanchis, P.; Guinjoan, F. Fuzzy Logic-Based Energy Management System Design for Residential Grid-Connected Microgrids. IEEE Trans. Smart Grid 2016, 9, 530-543. [CrossRef]

26. Arcos-Aviles, D.; Pascual, J.; Guinjoan, F.; Marroyo, L.; Sanchis, P.; Marietta, M.P. Low complexity energy management strategy for grid profile smoothing of a residential grid-connected microgrid using generation and demand forecasting. Appl. Energy 2017, 205, 69-84. [CrossRef]

27. Arcos-Aviles, D.; Guinjoan, F.; Pascual, J.; Marroyo, L.; Sanchis, P.; Gordillo, R.; Ayala, P.; Marietta, M.P. A Review of FuzzyBased Residential Grid-Connected Microgrid Energy Management Strategies for Grid Power Profile Smoothing. In Energy Sustainability in Built and Urban Environments; Motoasca, E., Kumar Agarwal, A., Breesch, H., Eds.; Springer: Singapore, 2019; pp. 165-199. [CrossRef]

28. Aviles, D.A.; Guinjoan, F.; Barricarte, J.; Marroyo, L.; Sanchis, P.; Valderrama, H. Battery management fuzzy control for a gridtied microgrid with renewable generation. In Proceedings of the IECON 2012-38th Annual Conference on IEEE Industrial Electronics Society, Montreal, QB, Canada, 25-28 October 2012; pp. 5607-5612. [CrossRef]

29. García-Gutiérrez, G.; Arcos-Aviles, D.; Carrera, E.V.; Guinjoan, F.; Motoasca, E.; Ayala, P.; Ibarra, A. Fuzzy Logic Controller Parameter Optimization Using Metaheuristic Cuckoo Search Algorithm for a Magnetic Levitation System. Appl. Sci. 2019, 9, 2458. [CrossRef]

30. Deepthi, S.; Ravikumar, A. A Study from the Perspective of Nature-Inspired Metaheuristic Optimization Algorithms. Int. J. Comput. Appl. 2015, 113, 53-56. [CrossRef]

31. Yang, X.-S. Nature-Inspired Optimization Algorithms, 1st ed.; Elsevier Inc.: London, UK, 2014.

32. Farzaneh, H.H.; Lindemann, U. A Practical Guide to Bio-Inspired Design; Springer: Berlin/Heidelberg, Germany, 2019.

33. Dey, N.; Ashour, A.S.; Bhattacharyya, S. (Eds.) Applied Nature-Inspired Computing: Algorithms and Case Studies; Springer: Singapore, 2020.

34. Jauhar, S.K.; Pant, M. Genetic Algorithms, a Nature-Inspired Tool: Review of Applications in Supply Chain Management. In Proceedings of the Fourth International Conference on Soft Computing for Problem Solving, Silchar, Assam, India, 27-29 December 2014; pp. 71-86. [CrossRef]

35. Khosravi, H.; Abolfazli-E, M.; Akbarzadeh-T, M.-R. A nature-inspired transition from Differential Evolution to Particle Swarm Optimization. In Proceedings of the 5th International Conference on Computer and Knowledge Engineering (ICCKE), Mashhad, Iran, 29 October 2015; pp. 87-92. [CrossRef]

36. Esmat, A.; Magdy, A.; ElKhattam, W.; Elbakly, A.M.; Magdy, A. A novel Energy Management System using Ant Colony Optimization for micro-grids. In Proceedings of the 3rd International Conference on Electric Power and Energy Conversion Systems, Istanbul, Turkey, 2-4 October 2013; pp. 1-6. [CrossRef]

37. Dey, B.; Shivam, K.; Bhattacharyya, B. Energy management of various microgrid test systems using swarm evolutionary algorithms. In Distributed Energy Resources in Microgrids; Chauhan, R.K., Chauhan, K., Eds.; Elsevier: London, UK, 2019; pp. 323-341. [CrossRef]

38. Singh, D.; Shukla, R.S. Development of Firefly Algorithm Interface for Parameter Optimization of Electrochemical-Based Machining Processes. In Applications of Firefly Algorithm and Its Variants; Dey, N., Ed.; Springer: Singapore, 2020; pp. 29-52. [CrossRef]

39. Mohanty, P.K.; Parhi, D.R. Optimal path planning for a mobile robot using cuckoo search algorithm. J. Exp. Theor. Artif. Intell. 2016, 28, 35-52. [CrossRef] 
40. Arcos-Aviles, D.; Garcia-Gutierrez, G.; Guinjoan, F.; Carrera, E.V.; Pascual, J.; Ayala, P.; Marroyo, L.; Motoasca, E. Adjustment of the Fuzzy Logic controller parameters of the energy management strategy of a grid-tied domestic electro-thermal microgrid using the Cuckoo search algorithm. In Proceedings of the IECON 2019-45th Annual Conference of the IEEE Industrial Electronics Society, Lisbon, Portugal, 14-17 October 2019; pp. 279-285. [CrossRef]

41. García-Gutiérrez, G.; Arcos-Aviles, D.; Carrera, E.V.; Guinjoan, F.; Ibarra, A.; Ayala, P. The Cuckoo Search Algorithm Applied to Fuzzy Logic Control Parameter Optimization. In Applications of Cuckoo Search Algorithm and its Variants; Springer Tracts in Nature-Inspired Computing; Dey, N., Ed.; Springer: Singapore, 2021; pp. 175-206. [CrossRef]

42. Civicioglu, P.; Besdok, E. A conceptual comparison of the Cuckoo-search, particle swarm optimization, differential evolution and artificial bee colony algorithms. Artif. Intell. Rev. 2013, 39, 315-346. [CrossRef]

43. Arcos-Aviles, D.; Guinjoan, F.; Pascual, J.; Marroyo, L.; Gordillo, R.; Sanchis, P.; Marietta, M.P.; Ibarra, A. Fuzzy-based energy management of a residential electro-thermal microgrid based on power forecasting. In Proceedings of the IECON 2018-44th Annual Conference of the IEEE Industrial Electronics Society, Washington, DC, USA, 21-23 October 2018; pp. 1824-1829. [CrossRef]

44. Arcos-Aviles, D.; Sotomayor, D.; Proaño, J.L.; Guinjoan, F.; Marietta, M.P.; Pascual, J.; Marroyo, L.; Sanchis, P. Fuzzy energy management strategy based on microgrid energy rate-of-change applied to an electro-thermal residential microgrid. In Proceedings of the IEEE 26th International Symposium on Industrial Electronics (ISIE), Edinburg, UK, 19-21 June 2017; pp. 99-105. [CrossRef]

45. Arcos-Aviles, D.; Guinjoan, F.; Marietta, M.P.; Pascual, J.; Marroyo, L.; Sanchis, P. Energy management strategy for a grid-tied residential microgrid based on Fuzzy Logic and power forecasting. In Proceedings of the IECON 2016-42nd Annual Conference of the IEEE Industrial Electronics Society, Florence, Italy, 23-26 October 2016; pp. 4103-4108. [CrossRef]

46. Marler, R.T.; Arora, J.S. The weighted sum method for multi-objective optimization: New insights. Struct. Multidiscip. Optim. 2010, 41, 853-862. [CrossRef]

47. Kennedy, J.N.; Eberhart, R.C. Particle swarm optimization. In Proceedings of the ICNN'95-International Conference on Neural Networks, Perth, WA, Australia, 27 November-1 December 1995; pp. 1942-1948. [CrossRef]

48. Eberhart, R.; Shi, Y. Particle swarm optimization: Developments, applications and resources. In Proceedings of the 2001 Congress on Evolutionary Computation, Seoul, Korea, 27-30 May 2001; pp. 81-86. [CrossRef]

49. Storn, R.; Price, K. Differential Evolution-A Simple and Efficient Heuristic for global Optimization over Continuous Spaces. J. Glob. Optim. 1997, 11, 341-359. [CrossRef]

50. Choi, J.H.; Lee, K.; Park, C. Differential Evolution; Springer: Berlin/Heidelberg, Germany, 2005.

51. Yang, X.; Press, L. Genetic algorithms. In Advances in Exploration Geophysics; Sen, M., Stoffa, P.L., Eds.; Elsevier: Amsterdam, The Netherlands, 1995; pp. 125-158. [CrossRef]

52. Fister, I., Jr.; Yang, X.S.; Fister, I.; Brest, J.; Fister, D. A brief review of nature-inspired algorithms for optimization. Elektroteh. Vestnik/Electrotech. Rev. 2013, 80, 116-122. 